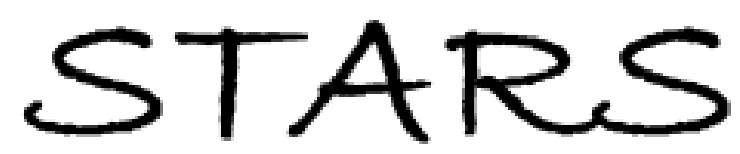

University of Central Florida

STARS

2009

\title{
A Multivariate Model Of Parent-adolescent Relationship Variables In Early Adolescence
}

Cliff McKinney

University of Central Florida

Part of the Psychology Commons

Find similar works at: https://stars.library.ucf.edu/etd

University of Central Florida Libraries http://library.ucf.edu

This Doctoral Dissertation (Open Access) is brought to you for free and open access by STARS. It has been accepted for inclusion in Electronic Theses and Dissertations, 2004-2019 by an authorized administrator of STARS. For more information, please contact STARS@ucf.edu.

\section{STARS Citation}

McKinney, Cliff, "A Multivariate Model Of Parent-adolescent Relationship Variables In Early Adolescence" (2009). Electronic Theses and Dissertations, 2004-2019. 3953.

https://stars.library.ucf.edu/etd/3953

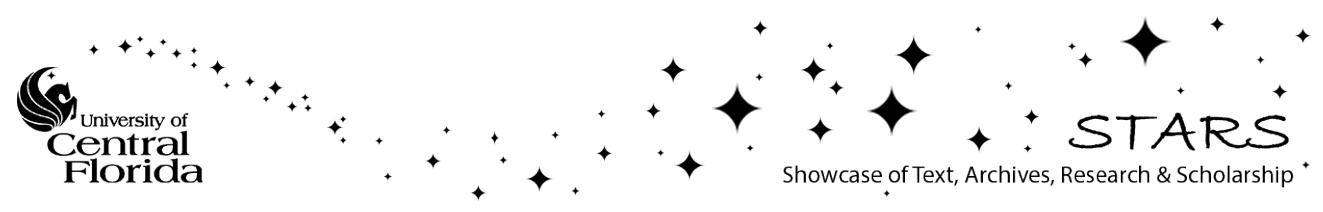




\title{
A MULTIVARIATE MODEL OF PARENT-ADOLESCENT RELATIONSHIP VARIABLES IN EARLY ADOLESCENCE
}

\section{CLIFF MCKINNEY}

M.S. University of Central Florida, 2004

\author{
A dissertation submitted in partial fulfillment of the requirements \\ for the degree of Doctor of Philosophy in Clinical Psychology \\ in the Department of Psychology \\ in the College of Sciences \\ at the University of Central Florida \\ Orlando, Florida
}

Spring Term

2009

Major Professor: Kimberly Renk 


\begin{abstract}
The purpose of this study is to examine a multivariate model of parent-adolescent relationship variables, including parenting, family environment, expectations and conflict. These variables are examined simultaneously to investigate their relationships with adolescent adjustment in early adolescence. The sample for the current study consists of 710 culturally diverse participants who range in age from 11- to 14-years and who attend a middle school in a Southeastern state. Of these participants, 487 have a mother and father who participated in this study as well. Correlational analyses indicate that parental warmth and overprotection, family cohesion and adaptability, developmental expectations, and conflict are significant predictors of internalizing and externalizing behavior problems in early adolescents. Structural equation modeling analyses indicate that fathers' parenting behaviors may not predict directly externalizing behavior problems in males and females but instead may act through conflict; more direct relationships exist when examining mothers' parenting behaviors. The impact of parenting, family environment, conflict, and sex on early adolescents' internalizing and externalizing behavior problems are emphasized.
\end{abstract}




\section{ACKNOWLEDGMENTS}

In appreciation of Dr. Kimberly Renk's mentorship and Dr. Jack McGuire’s, Dr. Ida Cook's, Dr. Florian Jentsch's, and Dr. Valerie Sims' constructive feedback. 


\section{TABLE OF CONTENTS}

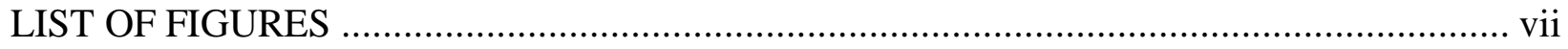

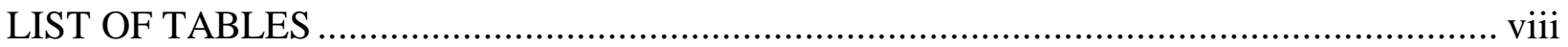

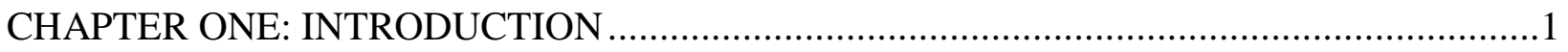

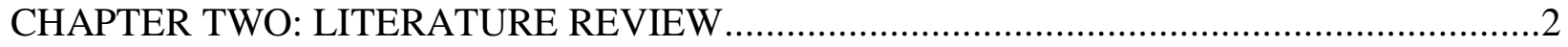

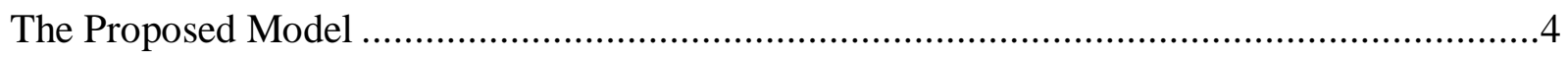

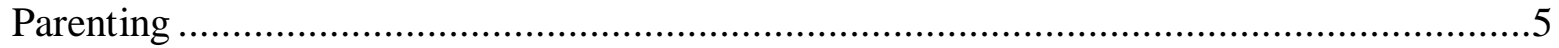

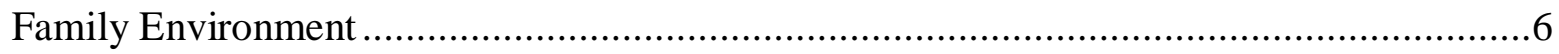

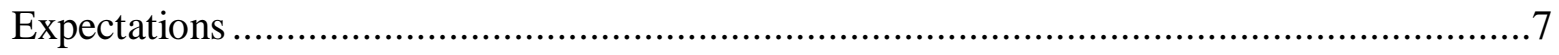

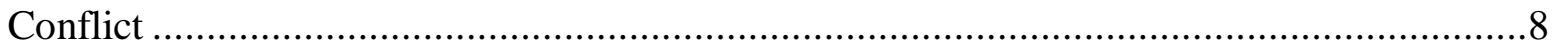

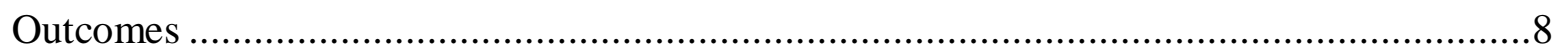

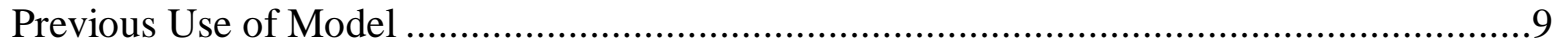

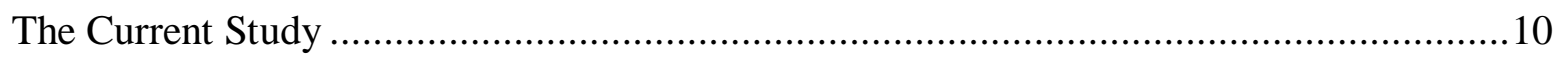

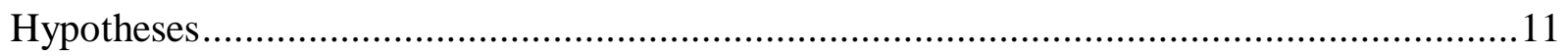

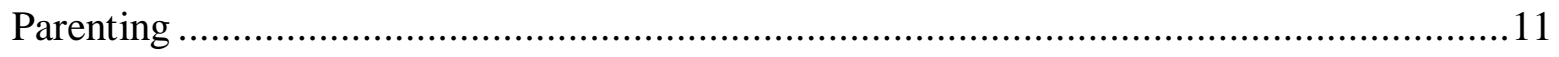

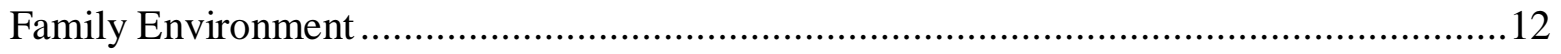

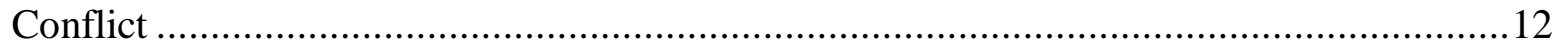

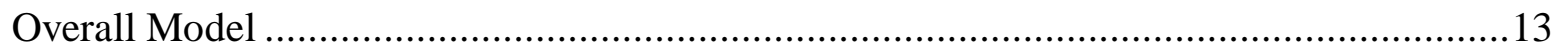

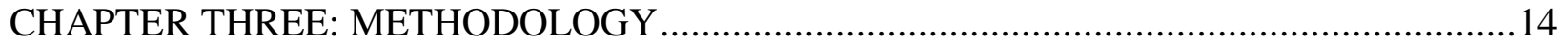

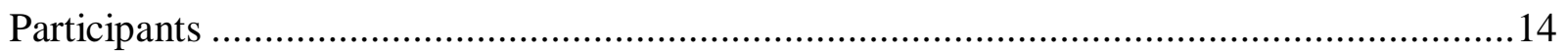

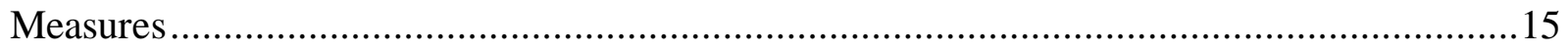

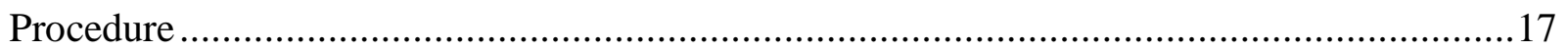

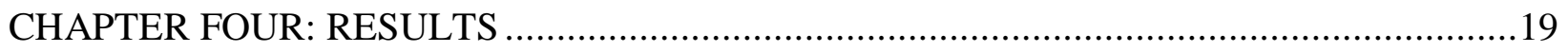




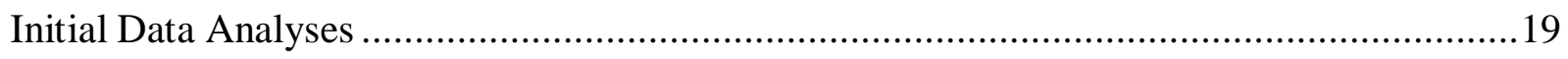

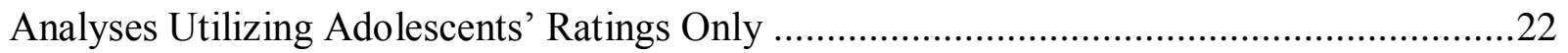

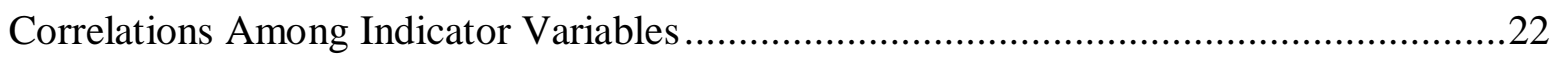

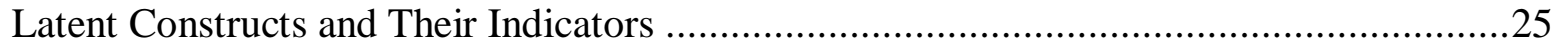

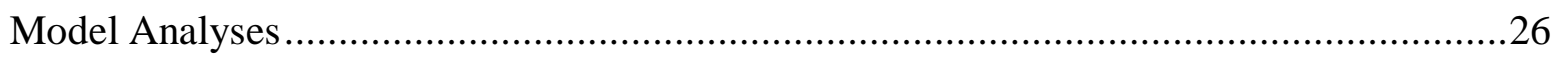

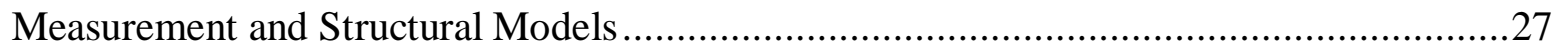

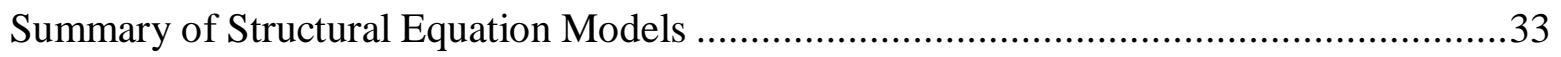

Analyses Using Ratings from Adolescents, Mothers, and Fathers: A Bigger Picture...............34

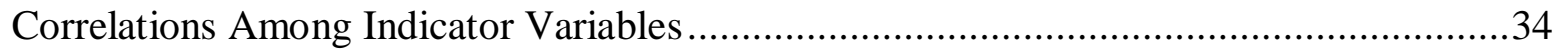

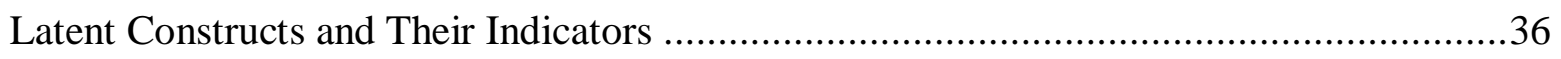

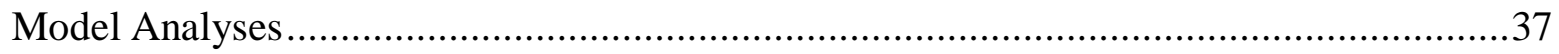

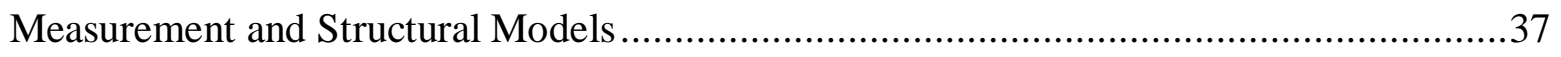

Summary of Structural Equation Models ……............................................................50

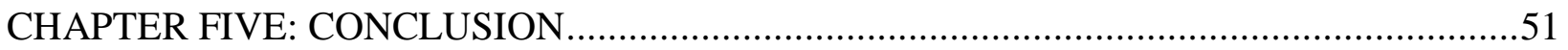

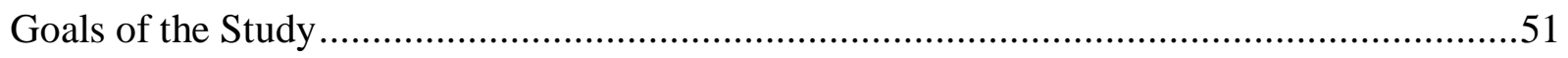

Cross-Informant Ratings and Cross-Sex Effects ..............................................................57

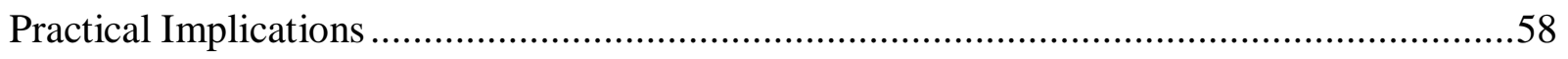

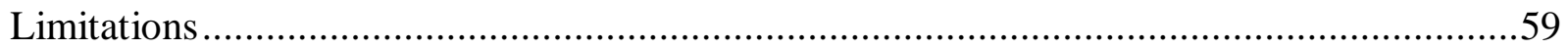

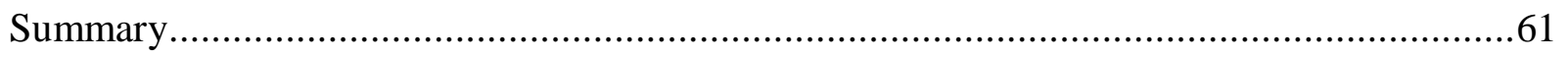

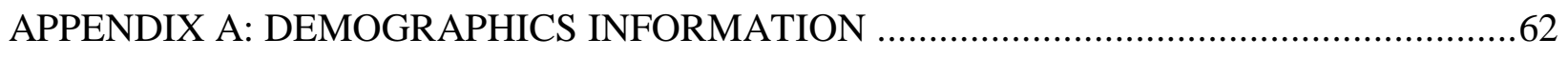

APPENDIX B: PARENTAL BONDING INSTRUMENT ……….......................................65

APPENDIX C: FAMILY ADAPTABILITY AND COHESION EVALUATION SCALE ........70

APPENDIX D: DEVELOPMENTAL TIMETABLES FOR ADOLESCENCE ………..............73 


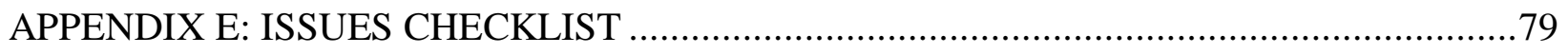

APPENDIX F: YOUTH SELF-REPORT/CHILD BEHAVIOR CHECKLIST .......................83

APPENDIX G: INFORMED CONSENT FORM ........................................................ 85

APPENDIX H: PERMISSION FORM .................................................................. 88

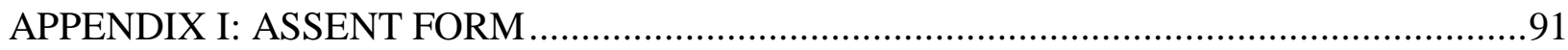

APPENDIX J: FACILITY CONSENT FORM ...................................................93

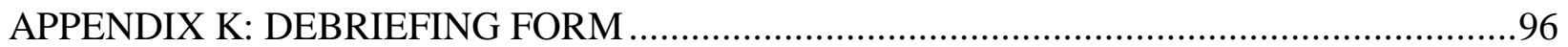

APPENDIX L: COVER LETTER ........................................................................ 98

APPENDIX M: INSTITIONAL REVIEW BOARD APPROVAL .................................... 100

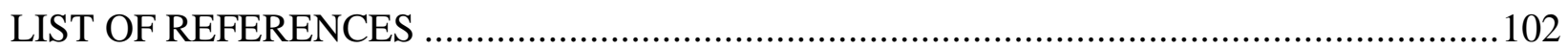




\section{LIST OF FIGURES}

Figure 1: Theoretical model of the interplay of parent-adolescent interaction variables.............11

Figure 2: Male measurement model: Adolescent ratings only. ............................................28

Figure 3: Female measurement model: Adolescent ratings only......................................29

Figure 4: Male fitted covariance structural model: Adolescent ratings only. ...........................31

Figure 5: Female fitted covariance structural model: Adolescent ratings only........................32

Figure 6: Male measurement model: Adolescent, mother, and father ratings combined. ............39

Figure 7: Female measurement model: Adolescent, mother, and father ratings combined. ........40

Figure 8: Male fitted covariance structural model displaying Mother-Internalizing Paths:

Adolescent, mother, and father ratings combined.

Figure 9: Male fitted covariance structural model displaying Mother-Externalizing Paths:

Adolescent, mother, and father ratings combined.

Figure 10: Male fitted covariance structural model displaying Father-Internalizing Paths:

Adolescent, mother, and father ratings combined.

Figure 11:Male fitted covariance structural model displaying Father-Externalizing Paths:

Adolescent, mother, and father ratings combined.

Figure 12: Female fitted covariance structural model displaying Mother-Internalizing Paths:

Adolescent, mother, and father ratings combined.

Figure 13: Female fitted covariance structural model displaying Mother-Externalizing Paths:

Adolescent, mother, and father ratings combined.

Figure 14: Female fitted covariance structural model displaying Father-Internalizing Paths:

Adolescent, mother, and father ratings combined.

Figure 15: Female fitted covariance structural model displaying Father-Externalizing Paths:

Adolescent, mother, and father ratings combined. 


\section{LIST OF TABLES}

Table 1: Means and Standard Deviations of Ratings by Adolescents ....................................20

Table 2: Means and Standard Deviations of Ratings by Parents ..........................................21

Table 3: Correlations Among Indicators for Males and Females: Adolescent Ratings ...............23

Table 4: Correlations Among Latent Constructs for Males and Females: Adolescent Ratings ....30

Table 5: Fit Indices for Covariance Structure Analyses: Adolescent Ratings .........................30

Table 6: Correlations Among Indicators for Males and Females: Mother Ratings .....................35

Table 7: Correlations Among Indicators for Males and Females: Father Ratings .....................35

Table 8: Correlations Among Latent Constructs for Males and Females: Adolescent, Mother, and

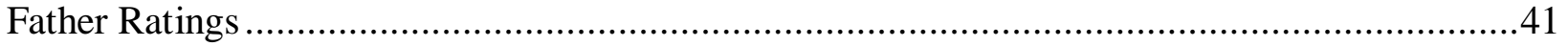

Table 9: Fit Indices for Covariance Structure Analyses: Adolescent, Mother, and Father Ratings 


\section{CHAPTER ONE: INTRODUCTION}

Many variables have been examined in an effort to understand parent-adolescent relationships and related adolescent outcomes. The literature now suggests that parent-adolescent variables must be integrated into a model that accounts for multivariate interplay and underlying processes in parent-adolescent relationships. A previous study (McKinney \& Renk, 2008) examines a multivariate model, in which parenting style, family environment, expectations, conflict, and emotional outcomes are assessed in the late adolescence period. The current study builds on this previous study by examining the outcomes of younger adolescents in the context of this previously tested multivariate model.

First, research on adolescent development is presented followed by a discussion of the proposed model and its variables and previous application. Research methodology is presented next followed by a discussion of the results and conclusions of the study. 


\section{CHAPTER TWO: LITERATURE REVIEW}

Few developmental time periods involve as much change as adolescence (Crean, 2008). As such, adolescent development is one of the most extensively studied child-related topics (Eisenberg et al., 2008). Many theoretical frameworks attempt to account for the processes and outcomes of adolescent development (Dekovic, 1999; Laursen \& Collins, 2004; Noack \& Puschner, 1999). Early theoretical frameworks rely on psychoanalytic theory and use the phrase 'storm and stress' to conceptualize adolescent development, especially when concerning parentadolescent relationships (Arnett, 1999; Eisenberg et al., 2008; Freud, 1968; Hall, 1904; Smetana, 2005). These frameworks propose that the normative pattern of adolescent development entails rebellion, excessive parent-adolescent conflict, and disengagement (Smetana, 1996, 2005). More recent research, however, shows that only 5 to $15 \%$ of families endure parent-adolescent relationships marked by chronic and intense levels of conflict (Eisenberg et al., 2008; Holmbeck, 1996). Thus, storm and stress theories may not be representative of all adolescents (Holmbeck, 1996; Smetana 2005).

Although normative adolescent development is no longer thought to involve the intense conflict and disengagement denoted in storm and stress theories, negative emotionality and closeness with parents do increase and decrease, respectively, during adolescence (Eisenberg et al., 2008). Further, individuation theory, a more recently developed theory, emphasizes the importance of individuality and connectedness during these developmental changes (Hofer, Youniss, \& Noack, 1998; Noack \& Kracke, 1998). This theory emphasizes a transactional relationship between adolescents and their parents, where positive emotional attachments allow adolescents to experience negative emotions and newly found autonomy in a supportive context (Eisenberg et al., 2008; Kostas, Henrick, Brookmeyer, \& Kuperminc, 2008). Thus, individuation 
serves as a process of relational transformations that lead to an increasingly mutual relationship between adolescents and their parents (Noack \& Puschner, 1999). These transformations are negotiated through conflicts over everyday issues, where adolescents and their parents negotiate their changing relationship as control and autonomy become more equal between parents and the adolescent (Eisenberg et al., 2008; Noack \& Kracke, 1998). Individuation theory also suggests that parent-adolescent relationships are characterized both by a moderate amount of conflict as well as closeness and support (Brooks-Gunn \& Zahaykevich, 1989; Hofer et al., 1998; Smetana, 2005; Steinberg, 1990). Thus, adolescents achieve individuality through conflict with their parents as well as with the support of their parents (Noack \& Puschner, 1999; Scabini, 2000).

Extant research demonstrates that more parent-adolescent relationships are better described using individuation theory relative to other types of experiences (e.g., storm and stress, little or no conflict; Hofer et al., 1998; Noack \& Kracke, 1998; Smetana, 1996). Further, an individuated pattern in parent-adolescent relationships appears to be the most beneficial for adolescent development due to its emphasis on high connectedness and individuality (Noack \& Puschner, 1999). In an effort to understand the parent-adolescent relationship variables that may promote positive adolescent outcomes, many researchers have examined a plethora of variables. Even so, little is known about the underlying processes of parent-adolescent relationship transformations (Brooks-Gunn \& Zahaykevich, 1989; Kostas et al., 2008; Paikoff \& BrooksGunn, 1991; Smetana, 1995; Steinberg, 1989, 1990). As Laursen and Collins (1994) note, "the complex interplay among context, maturation, and relationship characteristics is poorly understood" (p. 206). Thus, given the impact of parent-adolescent relationship variables on adolescent development and the "growing consensus among adolescent researchers that risk 
factors should be conceptualized in an integrative framework" (Henderson, Dakof, Schwartz, \& Liddle, 2006, p. 722), the need for a multivariate model is paramount.

McKinney and Renk (2008) describe and test such a model using a sample of late adolescents. Specifically, this model examines the interplay of parenting, family environment, expectations, conflict, and outcomes in late adolescents. In an effort to further validate this model, the current study will seek to extend this model to early adolescents who are in the midst of a time period where expectations may be changing rapidly and conflict may be particularly high (Crean, 2008; Eisenberg et al., 2008). Specifically, early adolescence may be an important stage in the development of the parent-adolescent relationship for several reasons. In particular, this time period is marked by changes in the parent-adolescent relationship, where adolescents may begin to strive actively for their own autonomy and resist parental authority (Crean, 2008; Kostas et al., 2008). As a result, more conflict in the parent-adolescent relationship is created, prompting early adolescence to be the time period where conflict is the highest (Crean, 2008; Kostas et al., 2008). Further, parents may find early adolescence to be particularly difficult, as their power may be compromised even though their adolescent is still young (Eisenberg et al., 2008).

\section{The Proposed Model}

The model proposed by McKinney and Renk (2008) and reexamined here is consistent with prior research that views conflict as the impetus for adaptation in parent-adolescent relationships. Through conflict, parents and adolescents adapt their expectations to the changing needs of their relationship. As adolescents strive toward autonomy, the parent-adolescent relationship transforms from a unilateral relationship, where power lies with the parents, to a 
mutual relationship, where the adolescent gains more independence over time and yet still needs parental support (Smetana, 2005).

In addition, parenting and the family environment play influential roles in determining how likely conflict over adolescents' autonomy is to facilitate or impede the realignment of parents' expectations for their adolescents (Baumrind, 1991; Ross, Marrinan, Schattner, \& Gullone, 1999; Yahav, 2006). Adolescents whose parents adjust their expectations through conflict to account for the developing autonomy of their adolescents may experience an increasingly mutual parent-adolescent relationship and better adjustment (Collins \& Luebker, 1994; Dekovic, Noom, \& Meeus, 1997; Laursen \& Collins, 2004). In contrast, adolescents whose parents do not adjust their expectations may experience an increasingly negative parentadolescent relationship and poorer adjustment (Collins \& Luebker, 1994; Dekovic et al., 1997; Laursen \& Collins, 2004). Overall, parenting style, family environment, expectations, and conflict may be critical in determining how smoothly adjustments are made in the parentadolescent relationship. Brief descriptions of these variables are provided below.

\section{Parenting}

Historically, styles of parenting have been derived from the dimensions of demandingness and responsiveness (Baumrind, 1991) or alternatively from support and control (Maccoby \& Martin, 1983). Seminal works suggest that parenting styles may be described as being authoritative, authoritarian, permissive, or neglecting (e.g., Baumrind, 1991). Parenting that is high in responsiveness and support and that includes a moderate level of control (i.e., authoritative parenting) appears to be the most beneficial style for children and adolescents, as it is related to several positive outcomes (Henderson et al., 2006; Holmbeck, 1996; PaulussenHoogeboom et al., 2008; Yahav, 2006). In contrast, parenting that lacks support and 
responsiveness but that is extremely high or low in control and high in rejection (i.e., authoritarian, permissive, or neglecting parenting) tends to be related to less positive outcomes for children and adolescents (Baumrind, 1991; Henderson et al., 2006; Paulussen-Hoogeboom et al., 2008; Yahav, 2006).

Early adolescents who are beginning to strive for their own autonomy present new challenges to parents (Crean, 2008; Eisenberg et al., 2008; Kostas et al., 2008). Authoritarian parents (i.e., parents who are lacking in responsiveness and are high in control) are not likely to respond to this challenge in a positive way. Instead, they may stifle adolescents' autonomy and remain rigid in their expectations for their adolescents (Paulussen-Hoogeboom et al., 2008). Parents who become more authoritarian in response to their adolescents' attempts to individuate also elicit increasingly negative exchanges and more disobedience (Dekovic, 1999; Henderson et al., 2006). In contrast, parents who are supportive and offer consistent, fair discipline (e.g., authoritative parents) facilitate an adaptive adjustment for their adolescents (Kotchick \& Forehand, 2002; Paulussen-Hoogeboom et al., 2008). In particular, parents may adapt to the changing status of their adolescents and not restrain the process by stifling their adolescents' individuation (Baumrind, 1991). Otherwise, early adolescents may challenge parents who dictate rules or overlook their rights (Comstock, 1994). Thus, parents who are able to create a cohesive family environment and adapt to the changing developmental goals of early adolescents will likely allow for a smoother transition with regard to their relationship with their adolescents (Eisenberg et al., 2008).

\section{Family Environment}

Family environments also play a critical role in adolescent development (Ross et al., 1999) and are related to a number of different adolescent characteristics, including independence, 
self-esteem, aggression, and anxiety (Demo, Small, \& Savin-Williams, 1987; Henderson et al., 2006; Lopez, Perez, Ochoa, \& Ruiz, 2008; Maccoby \& Martin, 1983; Yahav, 2006). In

particular, family environments that are typically cohesive and adaptable facilitate negotiations of parent-adolescent disagreements and decreases in conflict (Rueter \& Conger, 1995). When family environments are generally distant and rigid, adolescents and their parents encounter difficulty in resolving their disagreements (Rueter \& Conger, 1995). As a result, such environments may promote decreases in adolescents' self-esteem and happiness and increases in their aggression (Henderson et al., 2006; Lopez et al., 2008; Ross et al., 1999). Generally, early adolescents begin striving for autonomy from parental authority, and parents must adapt to their adolescents' increasing needs for autonomy and create a cohesive environment in which these needs may be expressed freely (Noom \& Dekovic, 1998). Successful adaptation leads to a more mutual parent-adolescent relationship, whereas failure to allow adolescents to individuate may lead to detachment (Krappman, Schuster, \& Youniss, 1998).

\section{Expectations}

One way that parents may facilitate the adaptation process is by adjusting their expectations of their adolescents so that they are developmentally appropriate (Dekovic et al., 1997). Violations of parents' expectations are most likely to occur throughout adolescents' rapid development, especially that which occurs in early adolescence when adolescents begin striving for more autonomy (Collins \& Luebker, 1994; Crean, 2008; Eisenberg et al., 2008; Kostas et al., 2008). Physical, social, and cognitive changes experienced by adolescents bring about repeated violations of expectancies that can lead to conflict. Warm, flexible parents may use this conflict as an opportunity to form new developmentally appropriate expectancies consistent with goals of autonomy and individuality, whereas harsh, strict parents may escalate the conflict in an attempt 
to maintain power over their adolescents (Collins \& Luebker, 1994; Dekovic et al., 1997;

Laursen \& Collins, 2004).

\section{Conflict}

Given these findings, negotiating conflict may be an important developmental task for adolescents and their parents (Gunlicks-Stoessel \& Powers, 2008). Conflict originates from developmental changes that prompt early adolescents to seek autonomy and may occur over a range of issues, including chores, rules, school, autonomy, privileges, and expectations (Eisenberg et al., 2008; Renk, Liljequist, Simpson, \& Phares, 2005). These types of conflict may realign expectations to be developmentally appropriate throughout adolescence, leading to an increasingly mutual parent-adolescent relationship (Eisenberg et al., 2008). In contrast, frequent and intense conflict that escalates throughout adolescence may lead to an increasingly negative parent-adolescent relationship (Collins \& Luebker, 1994; Eisenberg et al., 2008). Thus, conflict may play a pivotal role in informing parents that their adolescents' needs and expectations have changed and that adaptation is necessary (Holmbeck, 1996; Laursen \& Collins, 2004). Finally, conflict in the parent-adolescent relationship is related to adolescents' internalizing and externalizing behavior problems (Crean, 2008; Dekovic, 1999; Eisenberg et al., 2008; GunlicksStoessel \& Powers, 2008).

\section{Outcomes}

In general, family processes are related to outcomes for adolescents (Vazsonyi, 2004). Further, the type of reaction that adolescents and their parents have to conflict within the parentadolescent relationship determines greatly the extent of these outcomes (Holmbeck, 1996). Early adolescence may be particularly noteworthy with regard to these relationships, as this time 
period is marked by an increase in internalizing and externalizing behavior problems and may play a crucial role in laying the foundation for future development (Kostas et al., 2008). Conflict is found to be adaptive for parent-adolescent relationship outcomes when it facilitates the realignment of parent-adolescent relationships from a unilateral to a mutual relationship (Gunlicks-Stoessel \& Powers, 2008; Holmbeck, 1996; Smetana, 2005). Some outcomes, however, may not be adaptive if family members are not capable of making appropriate adjustments in the parent-adolescent relationship (Gunlicks-Stoessel \& Powers, 2008; Holmbeck, 1996; Smetana, 2005). In particular, persistent and intense conflict is associated with negative psychological outcomes, whereas low to moderate conflict that is resolved through adaptation in the parent-adolescent relationship is associated with more positive outcomes (Eisenberg et al., 2008; Grotevant \& Cooper, 1986; Gunlicks-Stoessel \& Powers, 2008).

\section{Previous Use of Model}

In a previous study by McKinney and Renk (2008), a multivariate model of parentadolescent relationship variables is tested in a college student sample with late adolescents who range in age from 18- to 22-years. This previous study examines the complex interplay of the parent-adolescent relationship variables described here and how that interplay is associated with outcomes for late adolescents. Briefly, findings of this previous study indicate that parenting, family environment, expectations, and conflict are related to outcomes for late adolescents but have different significant pathways based on the sex of both late adolescents and their parents. Several limitations of this previous study should be noted, however. First, although it is important to understand parent-adolescent relationships in late adolescence, no information about other developmental time periods is collected as part of this study. Thus, a large portion of adolescent development is unexamined in relation to the multivariate model that is tested. 
Further, the previous study examines a limited range of outcomes (i.e., internalizing outcomes only) and relies solely on the self-report of late adolescents (i.e., rather than using a crossinformant approach). Given these limitations, further examination of this model is warranted.

\section{The Current Study}

The purpose of the current study is to test a similar multivariate model (Figure 1), including similar parent-adolescent relationship variables, to that examined by McKinney and Renk (2008). Further, the current study strengthens key weaknesses of the previous study. The current study examines early adolescents instead of late adolescents and examines internalizing and externalizing behavior problems as outcomes instead of only internalizing behavior problems. Overall, the current study attempts to accomplish three things. First, the model in the current study attempts to predict parsimoniously early adolescent outcomes given information pertaining to the relationship variables described above. Second, the model in the current study attempts to pinpoint areas that are most critical to adolescent outcomes so that these areas may be suggested as the focus of potential interventions for adolescents who are experiencing difficulty in adapting throughout their adolescence. Third, the model in the current study attempts to integrate research concerning parent-adolescent relationship variables. 


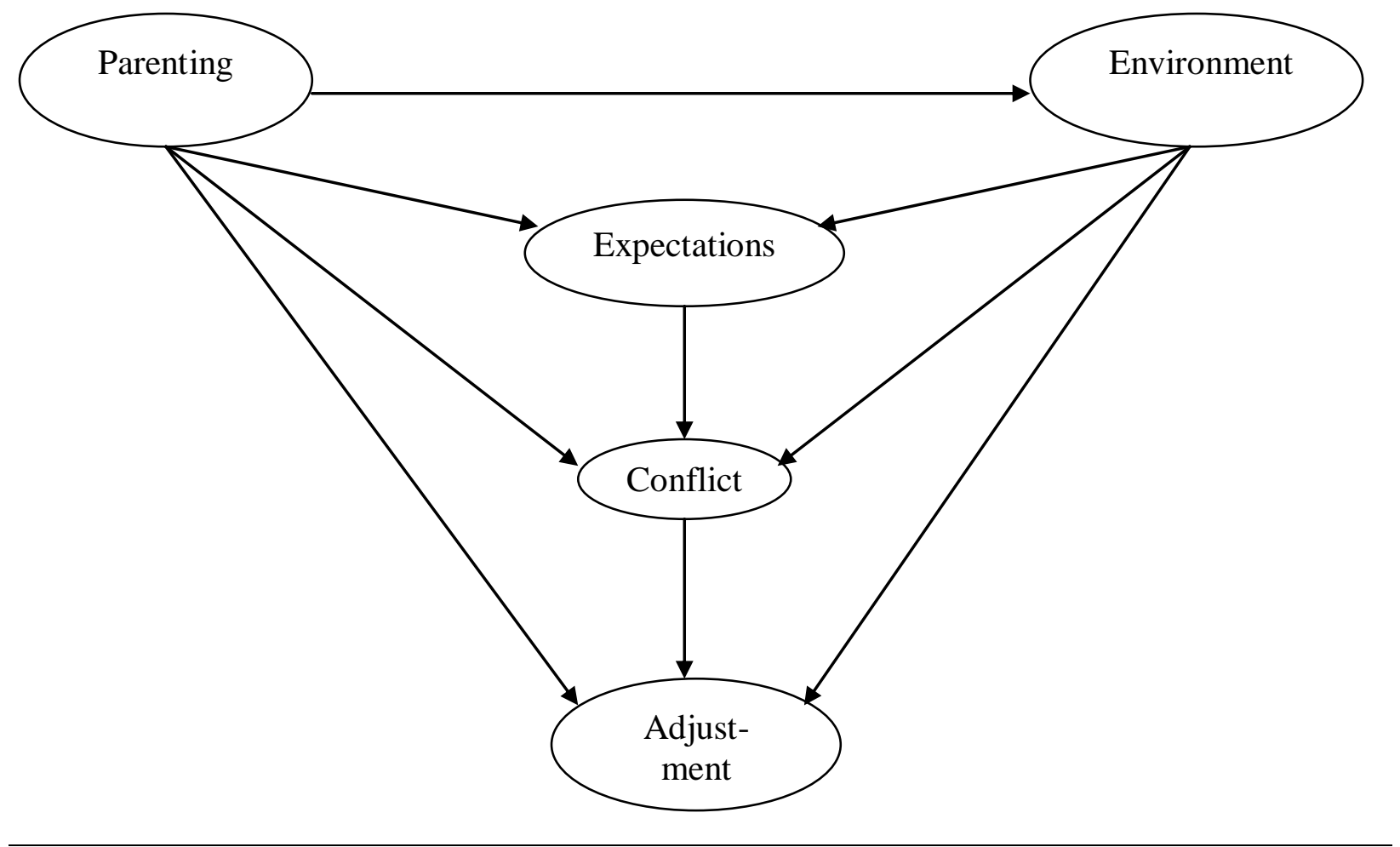

Figure 1: Theoretical model of the interplay of parent-adolescent interaction variables.

\section{Hypotheses}

\section{Parenting}

Hypothesis 1 states that adolescents' ratings of their parents' warmth will be related negatively to their ratings of their parents' expectations for them, positively to their ratings of their family's cohesion and adaptability, and negatively to their ratings of their own internalizing and externalizing behavior problems. Hypothesis 1 also states that adolescents' ratings of their parents' overprotection will be related positively to their ratings of their parents' expectations, negatively to their ratings of their family's cohesion and adaptability, and positively to their ratings of their own internalizing and externalizing behavior problems. This hypothesis is based on the finding that authoritative parenting tends to be associated with greater parental understanding and support (Baumrind, 1991). 


\section{Family Environment}

Hypothesis 2 states that adolescents' ratings of their family's cohesion and adaptability will be related negatively to their ratings of their parents' expectations and negatively to their ratings of their own internalizing and externalizing behavior problems. This hypothesis is based on the finding that cohesion and adaptability allow parents and adolescents to realign their expectations, leading to a decrease in the amount of conflict and, thus, more positive outcomes (Krappman et al., 1998; Lopez et al., 2008; Noom \& Dekovic, 1998).

\section{Conflict}

Hypothesis 3 states that parent-adolescent conflict will be related negatively to adolescents' ratings of parental warmth, positively to their ratings of parental overprotection, negatively to their ratings of their family's cohesiveness and adaptability, positively to their ratings of their parents' expectations for them, and positively to their ratings of their own internalizing and externalizing behavior problems. This hypothesis is based on findings that parents who create warm, supportive environments are capable of adapting their expectations to the changing needs of their adolescents without excessive conflict (Baumrind, 1991; Crean, 2008; Holmbeck, 1996; Krappman et al., 1998; Laursen \& Collins, 2004; Noom \& Dekovic, 1998; Smetana, 2005). Further, previous research suggests that conflict that elicits extreme negative emotions (i.e., emotions experienced as high in frequency and intensity and long in duration) may lead to the development of psychopathology (Crean, 2008; Gunlicks-Stoessel \& Powers, 2008). 


\section{Overall Model}

The above hypotheses state that adolescents' ratings of their parents' warmth and overprotection, their family's cohesion and adaptability, their parents' expectations, and the parent-adolescent conflict that they experience will predict their ratings of their internalizing and externalizing behavior problems. Further, Hypothesis 4 states that parenting and family environment will not have a direct effect on internalizing and externalizing behaviors when analyzed simultaneously with the other variables described here. Instead, it is anticipated that their effects will act through conflict (i.e., parenting and family environment accounted for individually will be related to internalizing and externalizing behavior problems, but these relationships will be eliminated when accounting simultaneously for conflict). Specifically, consistent with the literature cited above, it is anticipated that warm, flexible parents will use

conflict to facilitate the realignment of their expectations for their adolescents, thereby resolving future conflict and improving their adolescents' behavior problems. Conversely, it is expected that harsh, strict parents will use conflict to maintain power, thereby increasing future conflict and worsening adolescents' behavior problems. 


\section{CHAPTER THREE: METHODOLOGY}

\section{$\underline{\text { Participants }}$}

The sample for this study consists of 332 adolescent males and 378 adolescent females who range in age from 11 - to 14 -years $(M=12.28, S D=0.94)$ and who are enrolled in a middle school in the central region of Florida. The sample consisted of Hispanic (58.3\%), Caucasian (28.1\%), and African American (13.6\%) participants attending sixth, seventh, or eighth grade. All participants live with a mother and father figure (i.e., $69 \%$ of participants live with both of their biological parents, $29 \%$ of participants live with their biological mother and stepfather, and $2 \%$ of participants live with their biological father and stepmother). On average, adolescents in this sample report spending between two and three hours per day with their mothers and between one and two hours per day with their fathers. This finding appears to be consistent with time diaries indicating that mothers and fathers spend 12.9 and 6.5 hours, respectively, per week with their children in primary care activities (Bianchi, Robinson, \& Milkie, 2006).

Parents of participants were requested to participate as well. Parental participation (i.e., where both a mother and father figure completed a packet for their adolescent) included 220 cases for adolescent males and 267 cases for adolescent females. Mothers in this sample range in age from 27 - to 49 -years $(M=36.45, S D=5.27)$ and vary in their education backgrounds (with a range of eight to 20 years of education $[M=14.78, S D=1.03])$. Fathers in this sample range in age from 28- to 52-years $(M=38.71, S D=5.63)$ and vary in their educational backgrounds (with a range of 10 to 20 years of education $[M=15.52, S D=1.19])$. On average, mothers report spending between two and three hours per day with their adolescent, and fathers report spending between one and two hours per day with their adolescent. 


\section{$\underline{\text { Measures }}$}

Demographics Questionnaire (Appendix A). A demographics questionnaire was used to gain pertinent information about participants. Items include questions about participants' age, sex, ethnicity, parental education, living situation, and time spent with parents.

Parental Bonding Instrument (Appendix B). The Parental Bonding Instrument (PBI;

Parker, Tupling, \& Brown, 1979) has two scales designed to measure paternal and maternal care (opposite extreme being rejection) and overprotection (opposite extreme being autonomy granting). These scales exhibit good to excellent reliability and validity in previous studies. In this study, the care and overprotection scales (with alphas ranging from .81 to .88) are used as indicators of parenting. Higher scores indicate higher levels of care and overprotection, and lower scores indicate higher levels of rejection and autonomy granting, respectively. Adolescent participants completed the measure with regard to both their mothers and fathers, and mother and father participants completed the measure with regard to their own parenting.

Family Adaptability and Cohesion Evaluation Scale (Appendix C). The Family Adaptability and Cohesion Evaluation Scale (FACES-II; Olson, Bell, \& Portner, 1992) is designed to measure family adaptability (i.e., the ability to change) and cohesion (i.e., emotional connectedness). FACES-II demonstrates adequate internal consistency, test-retest reliability, and construct validity in previous studies. In this study, both scales (with alphas ranging from .78 to .90) are used as indicators of family environment. Higher scores indicate higher adaptability and cohesion, respectively. Adolescent participants and their mothers and fathers completed the measure with regard to their current family.

Developmental Timetables for Adolescence (Appendix D). Developmental Timetables for Adolescence (DTA; Dekovic et al., 1997) assesses maternal and paternal expectations for the 
mastery of developmental tasks by adolescents. The developmental tasks included on this measure describe personal, relational, and socioinstitutional tasks. Adolescent participants decide the age at which they believe their mothers and fathers expect them to engage in the tasks listed in each item, and mother and father participants decide the age at which they believe their adolescent is expected to engage in the tasks listed in each item. In previous studies, this measure has alphas ranging from .53 to .83 on its various subscales. In this study, the items from the three subscales (alphas ranging from .65 to .88) are combined into an overall score and used as a predictor of expectations. A higher overall score indicates later expectations for developmental tasks. Adolescent participants completed this measure with regard to both their mothers and fathers, and mother and father participants completed this measure with regard to their adolescent.

Issues Checklist (Appendix E). The Issues Checklist (IC; Prinz, Foster, Kent, \& O’Leary, 1979; Robin \& Foster, 1989) measures parent-adolescent conflict. This measure is a 44-item instrument consisting of issues that represent possible areas of conflict between adolescents and their parents. It yields two scores (i.e., frequency of conflict and intensity of conflict), which are converted into a single weighted score in this study (with a range of 0 to 5). Higher scores indicate a higher frequency and intensity of conflict. Adolescent participants and their mothers and fathers completed the measure with regard to the conflict that occurs in their families.

Youth Self Report and Child Behavior Checklist (Appendix F). The Youth Self Report (YSR) and the Child Behavior Checklist (CBCL; Achenbach \& Rescorla, 2001) assess a broad range of internalizing (e.g., anxiety and depression) and externalizing (e.g., aggression and impulsivity) symptoms that reflect the emotional and behavioral functioning of children and adolescents. These measures are used widely for assessing the functioning of children and 
adolescents. Internalizing Problems and Externalizing Problems scale scores have a normative mean of 50 and standard deviation of 10 . These scales are used in this study as predictors of internalizing and externalizing behavior problems. Higher scores indicate higher levels of each type of problem. Adolescent participants completed the YSR with regard to their own functioning, and mother and father participants completed the CBCL with regard to their adolescent's functioning.

\section{Procedure}

After the university institutional review board and the selected county's review board approved this study, the investigator contacted various middle schools in an attempt to solicit their participation in this study. School principals were asked to indicate permission for their school's participation using a Facility Approval Form (Appendix J). One principal from one middle school provided permission. During the first data collection, the investigator worked with this school's administrative staff to provide packets to classroom teachers, who distributed packets to students in their classrooms. Packets included a Cover Letter (Appendix L), a Consent Form (Appendix G) for mothers' and fathers' participation, parent forms of the measures, a Permission Form (Appendix H) so that parents could provide their consent for their adolescent's participation, an Assent Form (Appendix I) for students to indicate their agreement to participate, adolescent forms of the measures, and a Debriefing Form (Appendix K). Students were instructed to provide their parents with the packet so that they could receive consent from their parents to participate. Students (and mothers and fathers, where agreeable) then completed their packets and returned them in a sealed envelope to their classroom teachers, who returned the packets to the school's administrative staff. The administrative staff stored the packets in a secured office at the school until the investigator could retrieve the packets. Participants 
completed the study anonymously, and a unique number was used for each family on their packets to allow matching of anonymous student packets with respective mother and father packets.

In an effort to obtain more data, a second data collection was conducted at a later date. Upon approval from the same school in the first data collection, the investigator distributed packets as described above to students as school was dismissed. This time, packets also included addressed, stamped envelopes to facilitate a direct return of the packets to the investigator. Again, participants completed the study anonymously, and a unique number for each family was used so that packets completed by students and their parents could be matched. Consent forms from the second data collection were compared against consent forms from the first data collection to ensure that participants did not participate twice. 


\section{CHAPTER FOUR: RESULTS}

\section{$\underline{\text { Initial Data Analyses }}$}

Demographic characteristics are analyzed to determine if any group differences exist in the data. No significant differences exist based on adolescents' age, adolescents' ethnicity, or mothers' and fathers' education. Further, no significant differences are found among parent groups (i.e., biological mother and biological father, biological mother and stepfather, or stepmother and biological father) or between the first and second data collections. Although some research indicates that there are differences among Hispanic, Caucasian, and African American populations on internalizing and externalizing behavior problems, other research has found no such differences and is consistent with this study (McLaughlin, Hilt, \& NolanHoeksema, 2007). Further, differences by adolescents' age and mothers' and fathers' years of education may not have been found due to the small ranges present in this study.

Given the recent research suggesting that maternal and paternal influences should be considered independently for male and female adolescents (Bosco, Renk, Dinger, Epstein, \& Phares, 2003; Eisenberg et al., 2008; Holmbeck, Paikoff, \& Brooks-Gunn, 1995; Kostas et al., 2008; Lopez et al., 2008; McKinney \& Renk, 2008; Moon \& Hoffman, 2008; Paulson \& Sputa, 1996; Sim, 2003), $t$-test analyses are used to compare means for male and female adolescent participants' ratings as well as for mother and father participants' ratings. Examination of the ratings provided by the adolescent participants using $t$-tests indicate that both male and female ratings differ significantly at the $p<.05$ level on over a third of the measures. Mothers' ratings also differ significantly from fathers' ratings at the $p<.05$ level across several measures. See 
Table 1 for adolescent participants' means and standard deviations and Table 2 for mother and father participants' means and standard deviations.

Table 1: Means and Standard Deviations of Ratings by Adolescents

\begin{tabular}{lllll}
\multicolumn{2}{c}{ Male Adolescents } & & \multicolumn{2}{c}{ Female Adolescents } \\
\cline { 5 - 6 } Fathers & Mothers & & Fathers & Mothers
\end{tabular}

\begin{tabular}{llllllllc} 
Indicator & $M$ & $S D$ & $M$ & $S D$ & $M$ & $S D$ & $M$ & $S D$ \\
\hline PBI Warmth & 18.91 & 5.22 & 21.46 & 5.91 & 19.93 & 6.90 & 23.24 & 6.40 \\
PBI Overprotection & 15.20 & 4.70 & 18.19 & 4.01 & 13.45 & 7.02 & 16.88 & 5.31 \\
FACES-II Cohesion & 39.22 & 12.48 & -- & -- & 37.06 & 11.30 & -- & -- \\
FACES-II Adapt. & 37.21 & 11.44 & -- & -- & 34.57 & 12.60 & -- & -- \\
DTA & 131.51 & 30.06 & 153.00 & 30.64 & 136.01 & 28.34 & 161.22 & 28.72 \\
IC Weighted Score & 2.80 & 1.22 & -- & -- & 3.07 & 1.06 & -- & -- \\
YSR Internalizing & 55.34 & 9.22 & -- & -- & 53.76 & 7.79 & -- & -- \\
YSR Externalizing & 53.82 & 9.30 & -- & -- & 51.84 & 8.08 & -- & - \\
\hline
\end{tabular}

Note. -- indicates that a variable has an overall mean instead of father/mother specific means. $N=$ 332 for male adolescents and $N=378$ for female adolescents. 
Table 2: Means and Standard Deviations of Ratings by Parents

\begin{tabular}{lllll}
\multicolumn{2}{c}{ Male Adolescents } & & \multicolumn{2}{c}{ Female Adolescents } \\
${ } \quad \underline{\text { Mothers }} }$ & & Fathers & Mothers
\end{tabular}

\begin{tabular}{lcccccccc} 
Indicator & $M$ & $S D$ & $M$ & $S D$ & $M$ & $S D$ & $M$ & $S D$ \\
\hline PBI Warmth & 20.05 & 7.25 & 22.39 & 7.20 & 21.52 & 7.18 & 23.79 & 6.17 \\
PBI Overprotection & 14.87 & 6.80 & 14.10 & 5.54 & 13.53 & 7.73 & 15.15 & 6.39 \\
FACES-II Cohesion & 48.61 & 17.18 & 46.11 & 16.07 & 50.02 & 18.94 & 47.51 & 14.53 \\
FACES-II Adapt. & 37.62 & 15.30 & 39.29 & 14.67 & 35.70 & 14.72 & 40.96 & 18.23 \\
DTA & 154.65 & 22.06 & 147.06 & 25.39 & 157.42 & 18.02 & 152.51 & 25.19 \\
IC Weighted Score & 1.73 & 1.44 & 2.44 & 1.28 & 1.95 & 1.32 & 2.23 & 1.04 \\
YSR Internalizing & 57.92 & 8.08 & 53.70 & 8.38 & 54.67 & 7.06 & 56.02 & 7.54 \\
YSR Externalizing & 59.34 & 9.42 & 54.05 & 9.40 & 54.71 & 8.62 & 57.88 & 8.20 \\
\hline
\end{tabular}

Note. $N=220$ for male adolescents and $N=267$ for female adolescents.

Given the previously cited research (Bosco et al., 2003; Eisenberg et al., 2008; Holmbeck et al., 1995; Kostas et al., 2008; Lopez et al., 2008; McKinney \& Renk, 2008; Paulson \& Sputa, 1996; Moon \& Hoffman, 2008; Sim, 2003) and these significant differences, male and female data are analyzed separately. Thus, data for male and female adolescents' correlations as well as male and female adolescent models are presented first. The male and female adolescent models without mother and father participants' data are based on a sample size of 332 and 378, respectively. To investigate the effects of mother and father participants' data, data for male and female adolescents' correlations as well as male and female adolescent models using only cases with complete adolescent, mother, and father data (i.e., complete adolescent ratings, mother ratings, and father ratings using listwise deletion) are presented second. These cross-informant 
models are a subset of the overall data set and are based on a sample size of 220 for male adolescents and 267 for female adolescents.

\section{Analyses Utilizing Adolescents' Ratings Only}

\section{Correlations Among Indicator Variables}

To examine Hypotheses 1 through 3, correlational analyses are conducted prior to completing structural equation models. See Table 3 for correlations from male and female adolescent participants' ratings. Significant correlations relevant to these hypotheses are described here. 
Table 3: Correlations Among Indicators for Males and Females: Adolescent Ratings

1. 2. 3. 4. 5. 6. 7. $\quad$ 8. $9 . \quad 10.11$.

1. PBI Maternal Warmth $1-.47 * .29 *-.28 * .36 * .51 *-.12 *-.19 *-.58 *-.66 *-.50 *$

2. PBI Maternal Overprotection -.42* 1 -.59* 10 -.18*-.29* .22* .50* $21 * .24 * .47 *$

3. PBI Paternal Warmth $\quad .24 *-.47 * 11-.48^{*} .23 * .19 *-.16 *-.32 *-.19 *-.33 *-.53 *$

4. PBI Paternal Overprotection $-.29 * .20 *-.53 * 1-.49 *-.28 * .26 * .37 * .50 * .24 * .36 *$

5. FACES-II Cohesion $\quad .36^{*}-.26^{*} .33^{*}-.30^{*} 1 \quad .66^{*}-.26^{*}-.25^{*}-.56^{*}-.35^{*}-.18^{*}$

6. FACES-II Adaptability . $45 *-.19 * .24 *-.22 * .62 * 11-.21 *-.18 *-.56 *-.24 *-.20 *$

7. DTA Maternal Expectations $-.17 * .22 *-.24 * .25 *-.25 *-.24 * 11 \quad .19 * .27 * .57 * .41 *$

8. DTA Paternal Expectations $\quad-.23 * .16^{*}-.34 * .27 *-.18^{*}-.31 * .27 * \quad 1 \quad .25 * \quad .24 * .23 *$

9. IC Weighted Score $\quad-.42 * .16 *-.36 * .16^{*}-.53 *-.53 * .25 * .24 * \quad 1 \quad .48 * .51 *$

10. YSR Internalizing Problems $-.58^{*} .23 *-.46 * .24 *-.36 *-.20 * .36 * .28 * .43 * \quad 1 \quad .58 *$

11. YSR Externalizing Problems -. $44 * .53 *-.56 * .48 *-.29 *-.19 * .23 * .33 * .32 * .50 * 1$

Note. Correlations for ratings by male adolescents are below, whereas ratings by female adolescents are above the diagonal. $N=332$ for male adolescents and 378 for female adolescents. ${ }^{*} p<.05$. 
With regard to both male and female adolescent participants' ratings, the Hypotheses 1 through 3 are supported. Supporting Hypothesis 1, maternal and paternal warmth as rated by male and female adolescent participants are correlated negatively with developmental expectations (i.e., higher warmth is associated with earlier expectations), positively with family adaptability and cohesion (i.e., higher warmth is associated with higher family adaptability and cohesion), and negatively with YSR internalizing and externalizing behavior problems (i.e., higher warmth is associated with lower levels of behavior problems). Also supporting Hypothesis 1, maternal and paternal overprotection as rated by male and female adolescent participants is correlated positively with developmental expectations (i.e., higher overprotection is associated with later expectations), negatively with family adaptability and cohesion (i.e., higher overprotection is associated with lower family adaptability and cohesion), and positively with YSR internalizing and externalizing behavior problems (i.e., higher overprotection is associated with higher levels of behavior problems).

Supporting Hypothesis 2, both family adaptability and cohesion as rated by male and female adolescent participants are correlated negatively with developmental expectations (i.e., higher family adaptability and cohesion are associated with earlier expectations) and negatively with YSR internalizing and externalizing behavior problems (i.e., higher family adaptability and cohesion are associated with lower levels of behavior problems). Supporting Hypothesis 3, the weighted score on the IC as rated by male and female adolescent participants is correlated negatively with warmth (i.e., higher conflict is associated with lower warmth), positively with overprotection (i.e., higher conflict is associated with higher overprotection), negatively with family adaptability and cohesion (i.e., higher conflict is associated with lower family adaptability and cohesion), positively with developmental expectations (i.e., higher conflict is associated with 
later expectations), and positively with YSR internalizing and externalizing behavior problems (i.e., higher conflict is associated with higher levels of behavior problems).

\section{Latent Constructs and Their Indicators}

To examine Hypothesis 4, structural equation modeling is used. The constructs examined in this study include parenting, family environment, expectations, conflict, and adjustment. The two subscales of the PBI (i.e., care and overprotection) are indicators for parenting. These variables represent how much control parents exert, how much autonomy that parents grant, and how warm or rejecting parents are in their parenting. The cohesion and adaptability subscales of the FACES-II are used as indicators of family environment. These variables indicate how close together and how flexible the family is overall. A single score was derived from the DTA and is used as an indicator for expectations. This variable measures expectations related to mastering developmental tasks. The IC weighted score is used as an indicator of conflict. This variable represents the frequency and intensity of conflict that is experienced over a variety of issues. The YSR internalizing and externalizing behavior problems are used as indicators of adjustment. Thus, parenting has four indicators, family environment has two indicators, expectations has two indicators, conflict has one indicator, and adjustment has two indicators, for a total of 11 indicators. The path from the latent construct of conflict to the IC weighted score indicator is set to 1 . This set value is used to avoid local under-identification since the IC score is considered to adequately measure conflict. Further, the internal consistency reliability of the IC measure does not provide a good representation of this measure as some of its items are rated as occurring frequently and others are rated as occurring rarely. 


\section{Model Analyses}

Structural equation modeling (SEM) analyses are conducted with Statistica SEPATH for this study. For the purposes of SEM, a male adolescent sample size of 332 and a female adolescent sample size of 378 are considered good (Kline, 1998). The generalized least squares to maximum likelihood (GLS-ML) method of covariance structure analysis is used, and all models are based on the assumption of uncorrelated residuals. Overall model fit is examined using the squared error of approximation (RMSEA), the comparative fit index $(C F I)$, and the parsimonious fit index (PFI). RMSEA values less than or equal to .10 (Kline, 1998) and $C F I$ values greater than or equal to .90 indicate acceptable model fit (Bentler, 1992). PFI values greater than or equal to .60 signify that a model is sufficiently parsimonious (James, Mulaik, \& Brett, 1982). Chi-square tests are not used to assess overall model fit in this study due to their sensitivity to sample size and other biases (James et al., 1982).

Similar to other research, a two-stage modeling approach is utilized (Anderson \& Gerbing, 1988). In stage 1, a measurement model that allows all latent constructs to correlate freely is developed and evaluated. In stage 2, structural analysis to test relationships among latent variables is conducted. This process allows structural relationships to be tested only after ensuring that latent variables are measured adequately. Exploratory procedures are used initially to create a suitable measurement model, and confirmatory procedures are used subsequently to test relationships among latent variables. This process decreases the possibility that relationships among latent variables will be misinterpreted due to poor construct measurement (Anderson \& Gerbing, 1988). 


\section{Measurement and Structural Models}

The measurement models, shown in Figure 2 and Figure 3, reproduce adequately the covariance matrix as indicated by the RMSEA (all <.10), CFI (all > .90), and PFI (all > .60) values. All factor loadings exceed .60 (all $p \mathrm{~s}<.0005$ ), indicating convergent validity. Intercorrelations of the latent constructs and model statistics for the measurement models are shown in Table 4 and 5. Upon specifying appropriate measurement models, the hypothesized structural model (Figure 1) is tested. Each structural model reproduces adequately the covariance matrix as indicated by the RMSEA (all <.10), CFI (all >.90), and PFI (all > .60) values shown in Table 5. Figure 4 and 5 display the structural models and their path coefficients. 


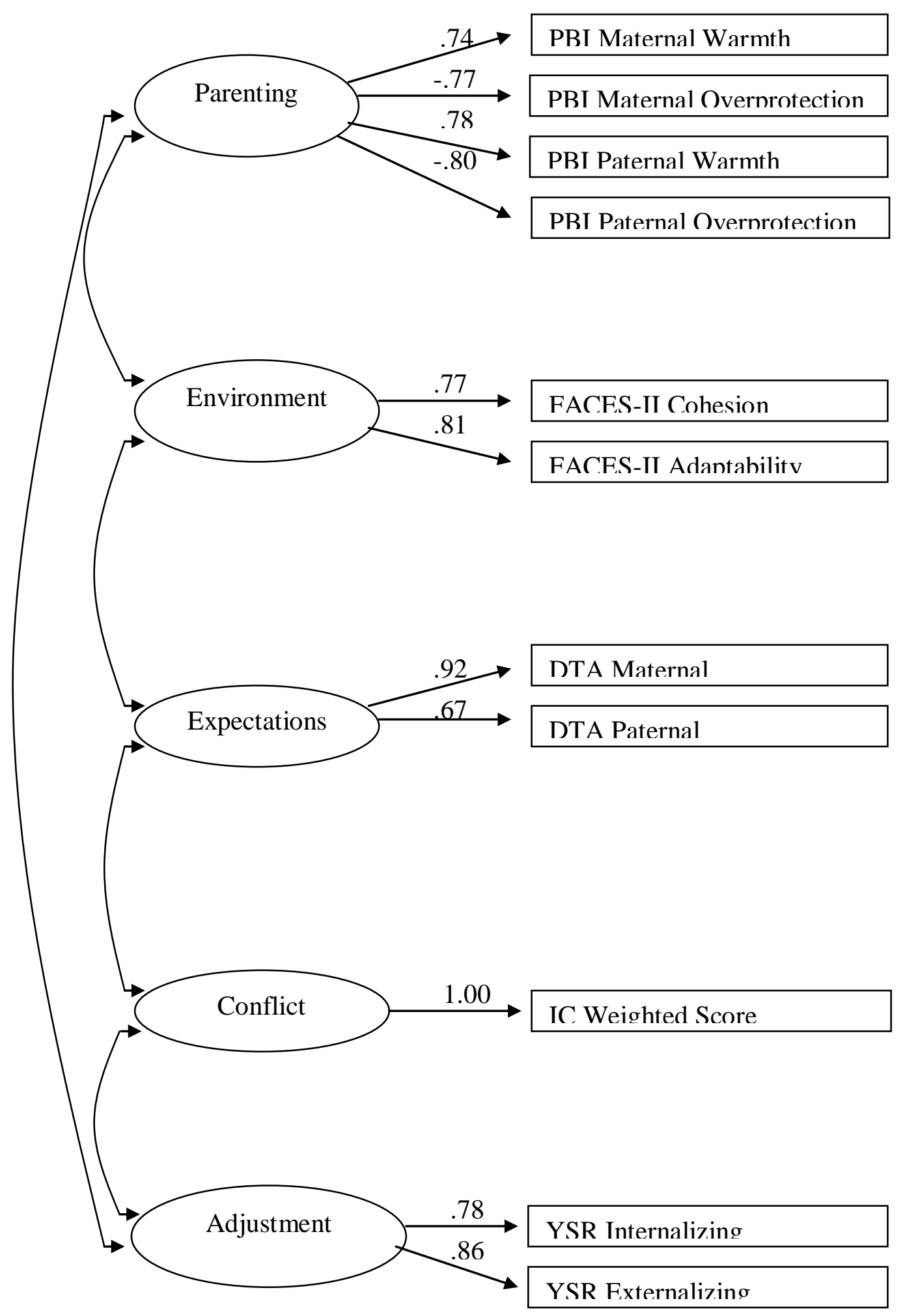

Figure 2: Male adolescent measurement model: Adolescent ratings only.

Note. Standardized factor loadings (all $p s<.0001$ ) appear above arrows. Measurement errors and factor correlations have been omitted for clarity. 


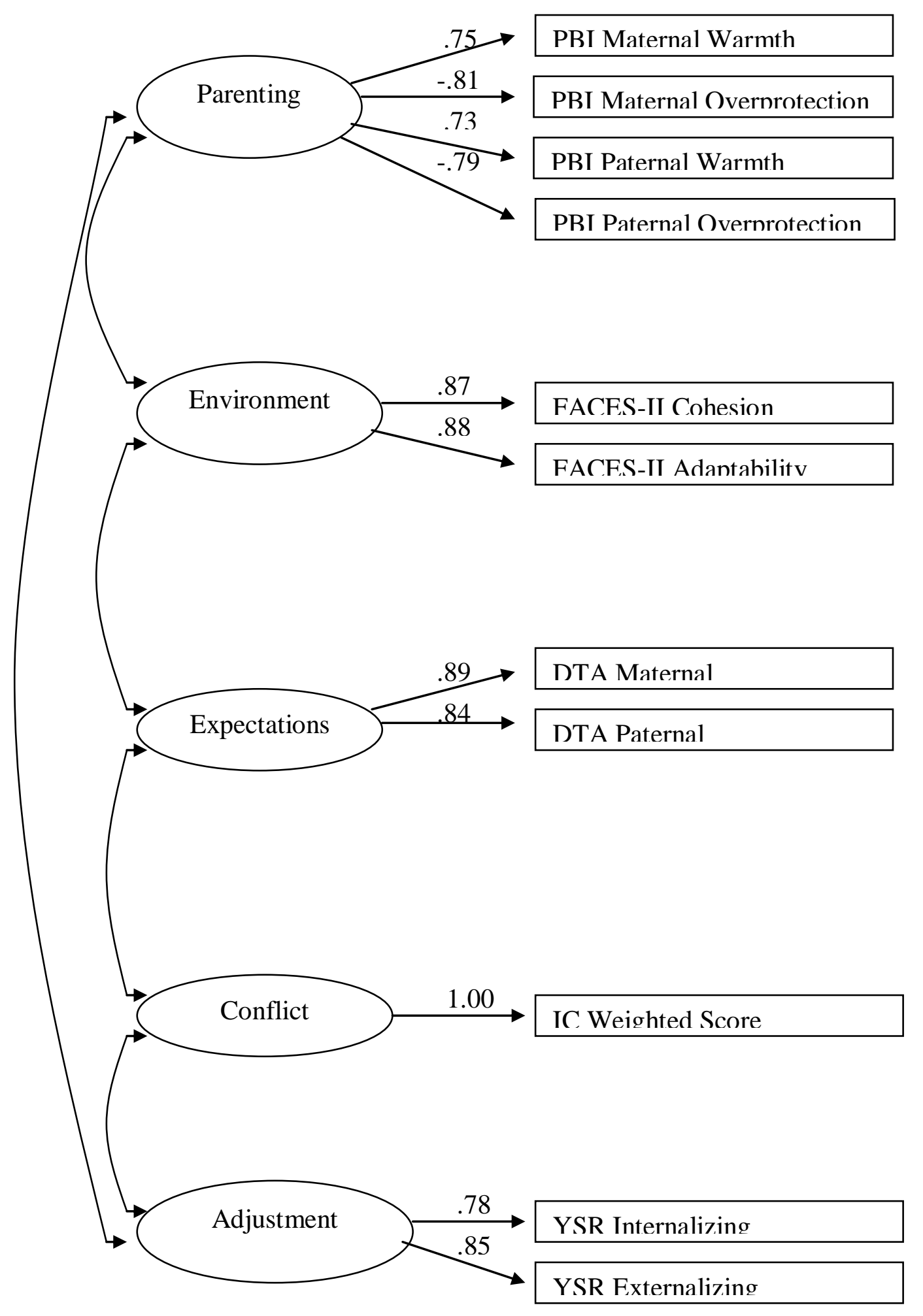

Figure 3: Female adolescent measurement model: Adolescent ratings only.

Note. Standardized factor loadings (all $p s<.0001$ ) appear above arrows. Measurement errors and factor correlations have been omitted for clarity. 
Table 4: Correlations Among Latent Constructs for Male and Female Adolescents: Adolescent Ratings

$$
\text { Parenting Environment Expectations Conflict Adjustment }
$$

\begin{tabular}{lccccc} 
Parenting & 1 & $.65^{*}$ & $-.45^{*}$ & $-.63^{*}$ & $-.65^{*}$ \\
Environment & $.44^{*}$ & 1 & $-.16^{*}$ & $-.74 *$ & $-.48^{*}$ \\
Expectations & $-.17^{*}$ & $-.19 *$ & 1 & $.34 *$ & $.21^{*}$ \\
Conflict & $-.52 *$ & $-.62^{*}$ & $.41^{*}$ & 1 & $.72^{*}$ \\
Adjustment & $-.72 *$ & $-.39 *$ & $.36^{*}$ & $.63 *$ & 1 \\
\hline
\end{tabular}

Note. Correlations for ratings by male adolescents are below, whereas ratings by female adolescents are above the diagonal. $N=332$ for male adolescents; $N=378$ for female adolescents. ${ }^{*} p<.05$

Table 5: Fit Indices for Covariance Structure Analyses: Adolescent Ratings Test Chi Squared df RMSEA CFI PFI $\underline{\text { Measurement models }}$

\begin{tabular}{llllll} 
Male adolescent ratings & 413.59 & 35 & .08 & .92 & .68 \\
Female adolescent ratings & 2388.33 & 35 & .10 & .90 & .63 \\
\hline & \multicolumn{1}{l}{ Structural models } & & & \\
Male adolescent ratings & 481.46 & 42 & .07 & .93 & .75 \\
Female adolescent ratings & 1705.85 & 42 & .09 & .91 & .73 \\
\hline
\end{tabular}

Note. $N=332$ for male adolescents; $N=378$ for female adolescents. 


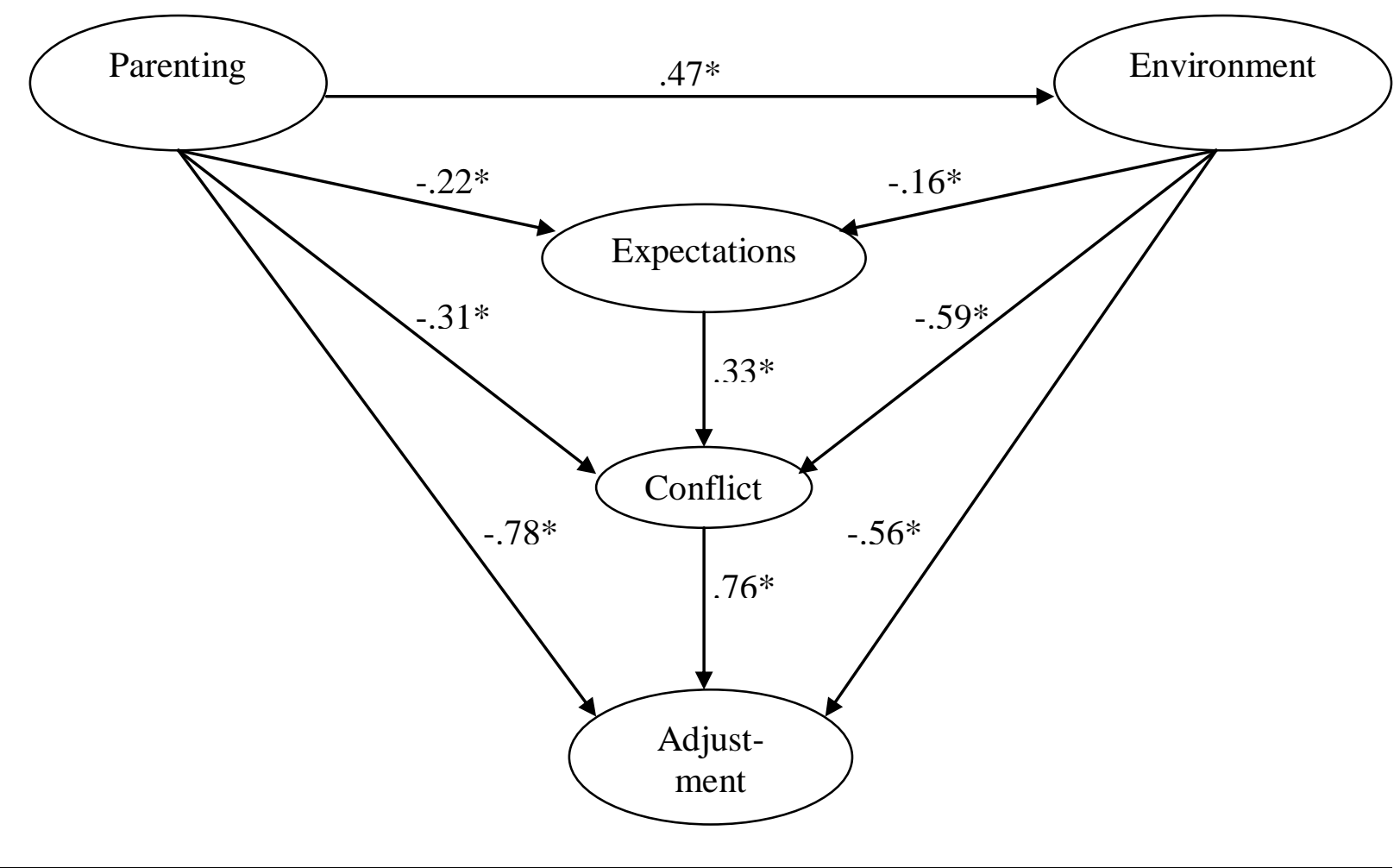

Figure 4: Male adolescent fitted covariance structural model: Adolescent ratings only.

Note. Asterisks label standardized parameter estimates for which $p<.05$. Disturbances and measurement error effects are omitted for clarity. 


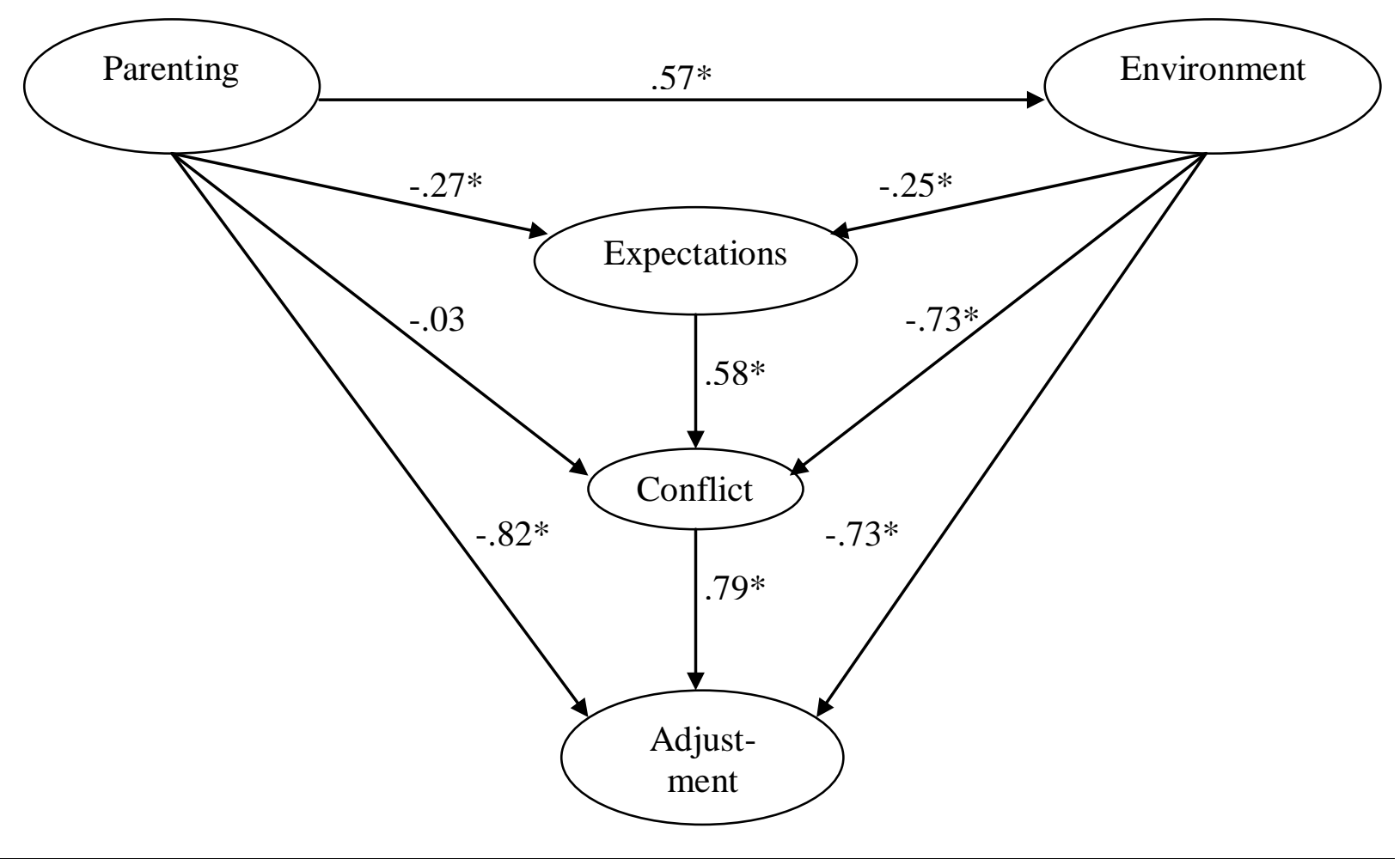

Figure 5: Female adolescent fitted covariance structural model: Adolescent ratings only. Note. Asterisks label standardized parameter estimates for which $p<.05$. Disturbances and measurement error effects are omitted for clarity. 


\section{Summary of Structural Equation Models}

Correlations among latent factors in the measurement model shown in Table 4 are examined in light of Hypotheses 1 through 3. These hypotheses also are supported using correlations among latent constructs (i.e., in a manner similar to the correlational analyses described above). According to the male and female adolescent structural models shown in Figure 4 and 5, respectively, Hypothesis 4 (i.e., that parenting and family environment would not have direct effects on adjustment) is not supported. The effects of parenting and family environment on adjustment remain significant in both the male and female adolescent models. When referring to path coefficients, strong indicates a path greater than or equal to .70 , moderate indicates a path greater than or equal to .30 and less than .70 , and modest indicates a path less than .30 .

In the male adolescent structural model, all path coefficients are statistically significant. Specifically, parenting is a strong predictor of adjustment, a moderate predictor of family environment and conflict, and a modest predictor of expectations. Family environment is a moderate predictor of conflict and adjustment and a modest predictor of expectations. Finally, expectations is a moderate predictor of conflict. Overall, adjustment in male adolescents is predicted strongly by parenting and conflict and moderately by family environment.

In the female adolescent structural model, all path coefficients are statistically significant with one exception. Similar to the male adolescent structural model, parenting is a strong predictor of adjustment, moderate predictor of family environment, and a modest predictor of expectations. In contrast to the male adolescent structural model, parenting does not predict conflict significantly. Family environment is a strong predictor of conflict and adjustment and a modest predictor of expectations. Finally, expectations are a moderate predictor of conflict. 
Overall, adjustment in adolescent females is predicted strongly by parenting, family environment, and conflict.

\section{Analyses Using Ratings from Adolescents, Mothers, and Fathers: A Bigger Picture}

Given the possible sex differences cited by previous research and given the statistically significant sex differences in male and female adolescents' ratings found in this study, male and female adolescent models are presented separately. Similar to the models described above, these models are based on adolescents' ratings as well as mothers' ratings and fathers' ratings. Thus, the data in this section is a subset of the overall data set (i.e., 220 male and 267 female adolescents had complete data from their mothers and fathers, whereas the remaining adolescent participants did not have complete mother and/or father data).

\section{Correlations Among Indicator Variables}

Table 6 and Table 7 present the correlation matrices for mothers' ratings and fathers' ratings, respectively. The correlations in this subset of the data are similar in direction and statistical significance to the adolescent correlations discussed previously. Thus, please refer to the correlational results discussed above. 
Table 6: Correlations Among Indicators for Male and Female Adolescents: Mother Ratings

$$
\text { 1. 2. 3. 4. 5. 6. } \quad \text { 7. } 8 \text {. }
$$

1. PBI Maternal Warmth 1 -.41*.29*.44*-.17*-.47*-.55*-.41*

2. PBI Maternal Overprotection -.32* 1 -.21*-.31*.25*.26* $.31 * .37 *$

3. FACES-II Cohesion $\quad .39 *-.29 * 1$. $15 *-.25 *-.36 *-.29 *-.38 *$

4. FACES-II Adaptability $.39 *-.17 * .49 * 1$ - 1 - $26 *-.44 *-.28 *-.41 *$

5. DTA Maternal Expectations $-.21 * .25 *-.21 *-.19 * \quad 1 \quad .33 * .43 * .35 *$

6. IC Weighted Score $\quad-.38 * .18 *-.46 *-.41 * .18 * \quad 1 \quad .47 * .42 *$

7. YSR Internalizing Problems $-.41 * .31 *-.41 *-.29 * .26 * .34 * 1 \quad .68 *$

8. YSR Externalizing Problems $-.38 * .44 *-.48 *-.29 * .33 * .36 * .71 * 1$

Note. Correlations for ratings of male adolescents are below, whereas ratings of female adolescents are above the diagonal. $N=220$ for male adolescents and 267 for female adolescents. $* p<.05$.

Table 7: Correlations Among Indicators for Male and Female Adolescents: Father Ratings

$$
\text { 1. 2. 3. 4. 5. 6. 7. } 8 \text {. }
$$

1. PBI Paternal Warmth $\quad 1 \quad-.43 * .39 * .47 *-.19 *-.55 *-.61 *-.59 *$

2. PBI Paternal Overprotection $-.39 * 1-.25 *-.35 * .19 * .21 * .25^{*} .38 *$

3. FACES-II Cohesion .26*-.31* 1 .48*-.22*-.44*-.47*-.26*

4. FACES-II Adaptability $.37 *-.28 * .51 * 1 \quad-.21 *-.49 *-.41 *-.31 *$

5. DTA Paternal Expectations $-.21 * .19 *-.31 *-.22 * \quad 1 \quad .26 * .17 * .18 *$

6. IC Weighted Score $\quad-.35 * .23 *-.58 *-.61 * .29 * \quad 1 \quad .37 * .55^{*}$

7. YSR Internalizing Problems $-.45 * .34 *-.39 *-.45 * .29 * .48 * 11 \quad .63 *$

8. YSR Externalizing Problems $-.59 * .41 *-.26 *-.28 * .28 * .39 * .59 * 1$

Note. Correlations for ratings of male adolescents are below, whereas ratings of female adolescents are above the diagonal. $N=220$ for male adolescents and 267 for female adolescents. ${ }^{*} p<.05$. 


\section{Latent Constructs and Their Indicators}

So that adolescents', mothers', and fathers' ratings could be incorporated into one model, several methods of organizing the constructs based on theory and the correlation matrix are attempted. First, indicators are loaded onto constructs as described above, with additional indicators from mothers' and fathers' ratings being loaded onto the same construct as their respective adolescent indicators (e.g., adolescents' rating of maternal warmth and overprotection and paternal warmth and overprotection are loaded onto the parenting construct along with mothers' ratings and fathers' ratings of these same variables). This configuration fails to adequately reproduce the covariance matrix as indicated either by multicollinearity or $R M S E A>$ .10 and $C F I<.90$, however, suggesting the need for respecification. The need for respecification is common, as "initially specified measurement models almost invariably fail to provide acceptable fit" (Anderson \& Gerbing, 1988, p. 412). A respecified measurement model that adequately reproduces the covariance matrix is derived for male and female adolescents.

After reconsidering the reconfiguration of these cross-informant models, the constructs included in the accepted models are similar to those in Figure 1 with two exceptions. For these cross-informant models, the parenting construct is divided into two constructs (i.e., maternal and paternal parenting) and the adjustment construct is divided into two constructs (i.e., internalizing behavior problems and externalizing behavior problems). Thus, final constructs include maternal parenting (with four indicators from the PBI, including adolescents' ratings of maternal warmth and overprotection and mothers' ratings of maternal warmth and overprotection), paternal parenting (with four indicators from the PBI, including adolescents' ratings of paternal warmth and overprotection and fathers' ratings of paternal warmth and overprotection), family

environment (with six indicators from the FACES-II, including adolescents', mothers', and 
fathers' ratings of family cohesion and family adaptability), expectations (with four indicators from the DTA, including adolescents' ratings of mothers' and fathers' expectations, mothers' ratings of their expectations, and fathers' ratings of their expectations), conflict (with three indicators from the IC weighted score, including adolescents' ratings, mothers' ratings, and fathers' ratings of conflict), internalizing behavior problems (with three indicators, including adolescents' ratings on the YSR and mothers' and fathers' ratings on the CBCL), and externalizing behavior problems (with three indicators, including adolescents' ratings on the YSR and mothers' and fathers' ratings on the $\mathrm{CBCL}$ ). Thus, 27 indicators are used.

\section{Model Analyses}

For the purposes of SEM, a male sample size of 220 and a female sample size of 267 are considered fair (Kline, 1998). Structural equation modeling (SEM) analyses are conducted with Statistica SEPATH in this study in the same manner as described above.

\section{Measurement and Structural Models}

The measurement models, shown in Figure 6 and Figure 7, reproduce adequately the covariance matrix, as indicated by the RMSEA (all <.10), CFI (all > .90), and PFI (all > .60) values. All factor loadings exceed .60 (all $p s<.0005$ ), indicating convergent validity. Intercorrelations of the latent constructs and model statistics for the measurement models are shown in Table 8 and 9. Upon specifying appropriate measurement models, the hypothesized structural model is tested. Each structural model reproduces adequately the covariance matrix, as indicated by the RMSEA (all <.10), CFI (all >.90), and PFI (all > .60) values shown in Table 9. Figure 8 through 15 display the structural models and their path coefficients. Please note that the 
constructs described above all are analyzed simultaneously for male and female models, but that Figure 8 through 15 separate graphically some of the constructs for clarity. 


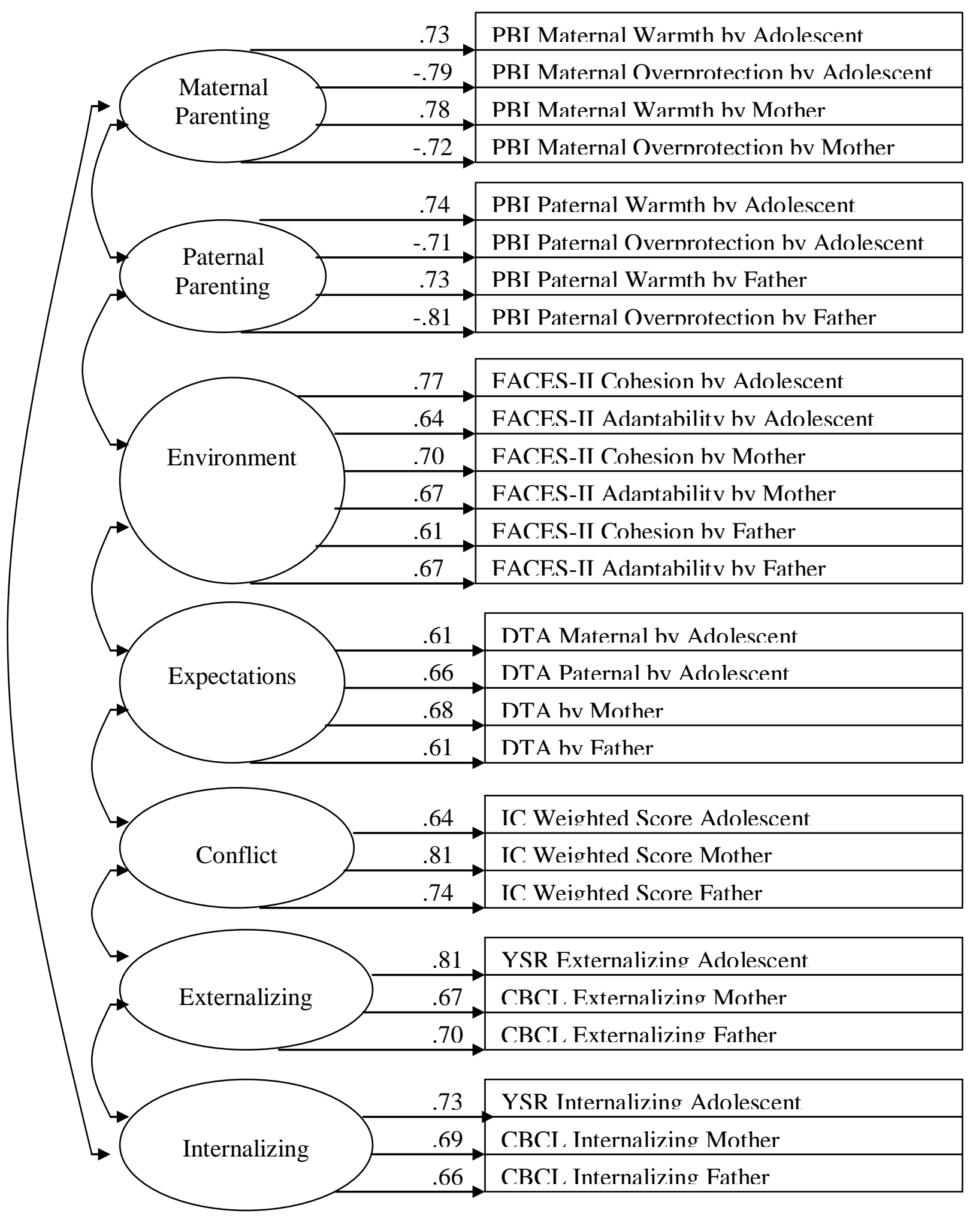

Figure 6: Male adolescent measurement model: Adolescent, mother, and father ratings combined. Note. Standardized factor loadings (all $p s<.0001$ ) appear above arrows. Measurement errors and factor correlations have been omitted for clarity. 


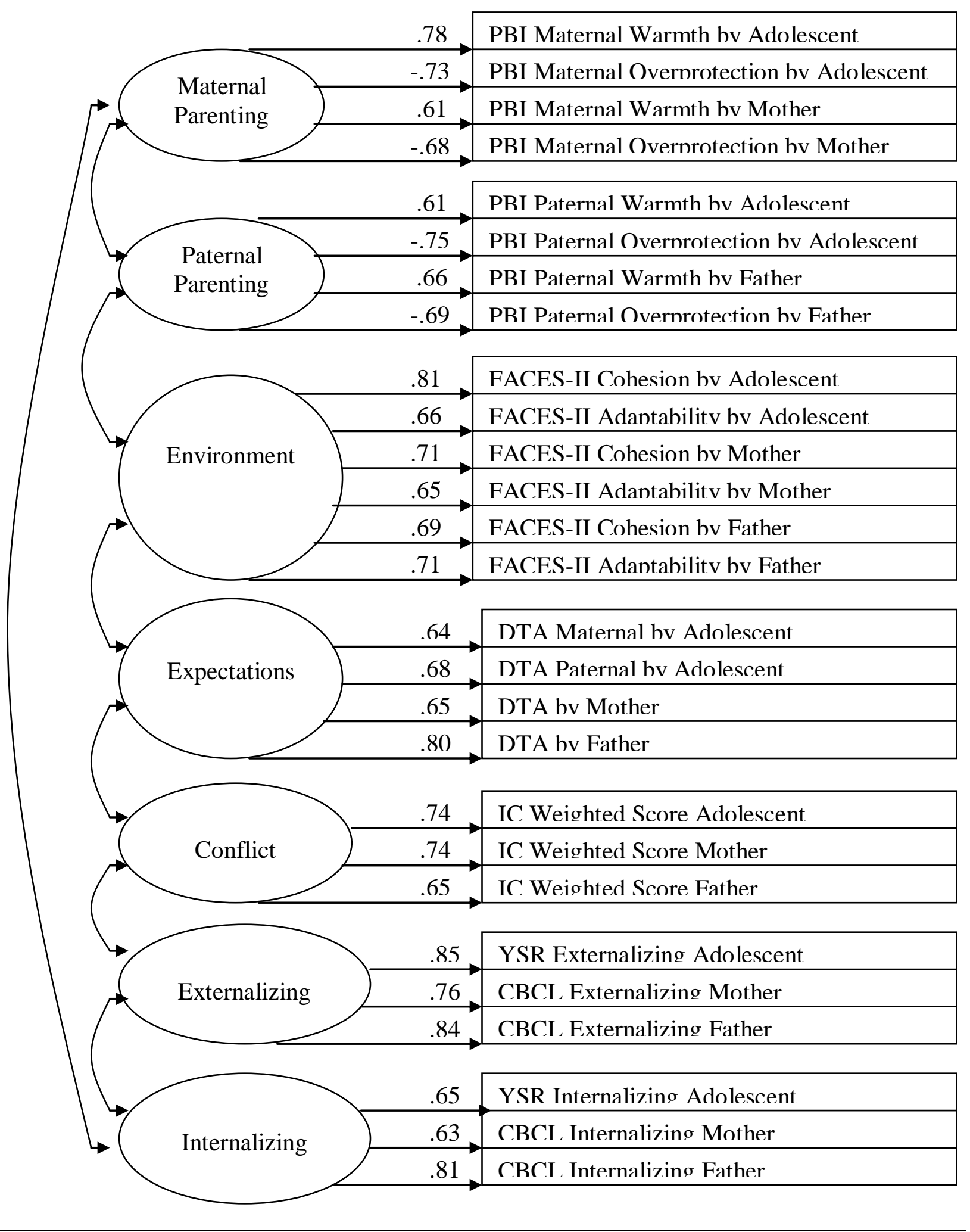

Figure 7: Female adolescent measurement model: Adolescent, mother, and father ratings combined. Note. Standardized factor loadings (all $p s<$.0001) appear above arrows. Measurement errors and factor correlations have been omitted for clarity. 
Table 8: Correlations Among Latent Constructs for Male and Female Adolescents: Adolescent, Mother, and Father Ratings

$$
\text { 1. } \quad \text { 2. } 3 . \quad \text { 4. } \quad \text { 5. } 6 . \quad 7 .
$$

1. Maternal Parenting $1 \quad .31 * \quad .48^{*}-.19^{*}-.55^{*}-.61^{*}-.58^{*}$

2. Paternal Parenting $.41 * \quad 1 \quad .35 *-.23 *-.22 *-.52 *-.57 *$

3. Environment $\quad .56 * \quad .43 * \quad 1 \quad-.21 *-.48 *-.55^{*}-.61 *$

4. Expectations $\quad-.21 * \quad-.19 *-.20 * \quad 1 \quad r .17 * \quad .21 * \quad .38 *$

5. Conflict $\quad-.42 * \quad-.31 *-.41 * \quad .21 * \quad 1 \quad .65 * \quad .72 *$

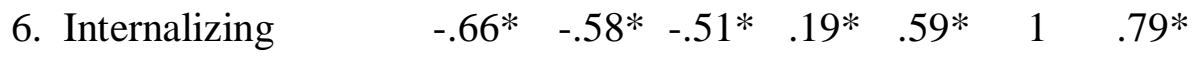

7. Externalizing $\quad-.71 *-.68 *-.55 * 23 * \quad .66 * \quad .77 * 1$

Note. Correlations for male adolescent ratings are below, whereas female adolescent ratings are above the diagonal. $N=220$ for male adolescents; $N=267$ for female adolescents. $* p<.05$

Table 9: Fit Indices for Covariance Structure Analyses: Adolescent, Mother, and Father Ratings Test Chi Squared $\quad d f \quad$ RMSEA CFI PFI

\section{$\underline{\text { Respecified Measurement models }}$}

$\begin{array}{lllllll}\text { Male adolescent ratings } & 2256.07 & 300 & .10 & .91 & .61\end{array}$

Female adolescent ratings

2931.87

300

.10

.90

.65

$\underline{\text { Structural models }}$

$\begin{array}{llllllll}\text { Male adolescent ratings } & 1786.73 & 306 & .09 & .92 & .69\end{array}$

Female adolescent ratings

2207.02

306

.10

.92

.72

Note. $N=220$ for male adolescents; $N=267$ for female adolescents. 


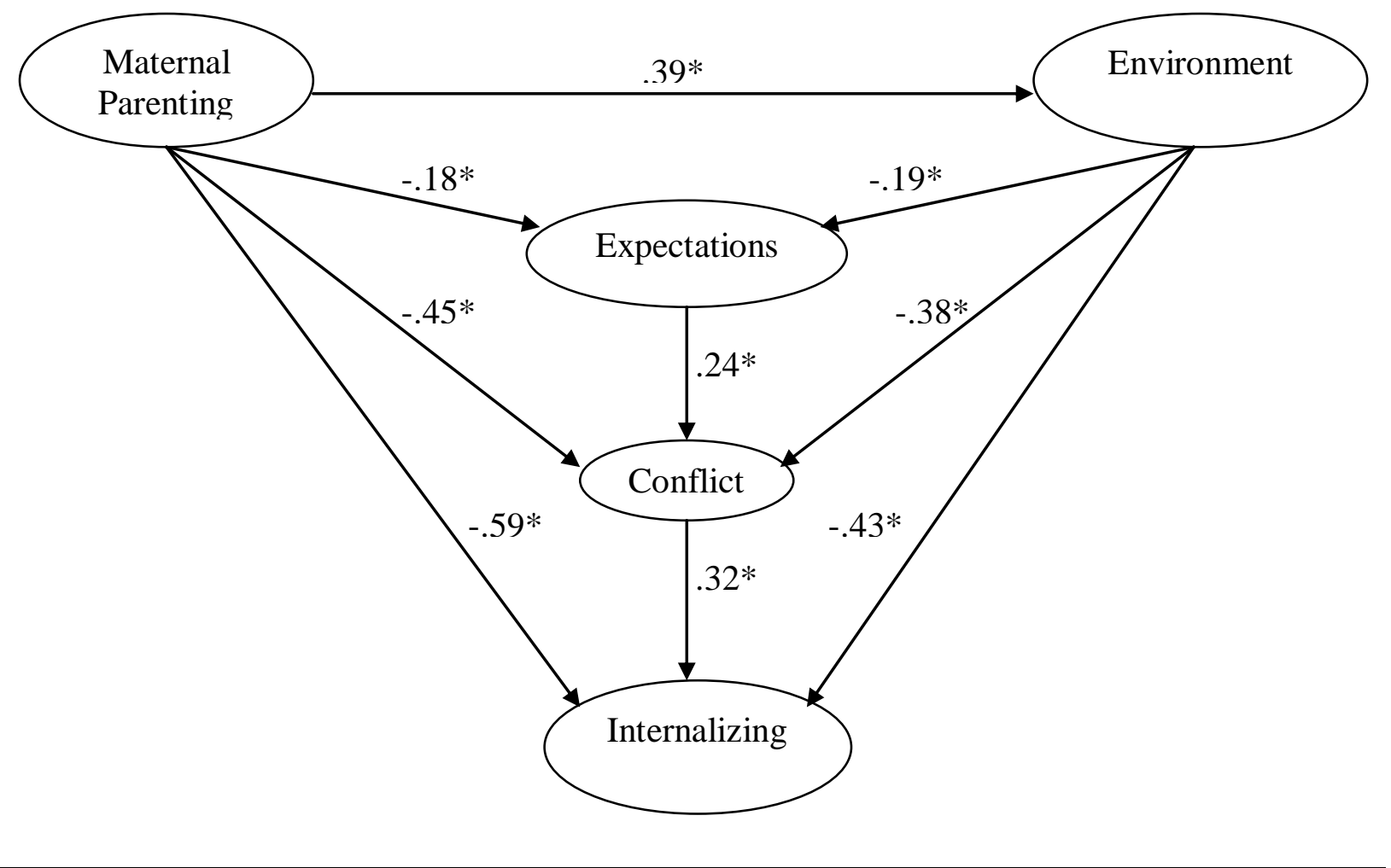

Figure 8: Male adolescent fitted covariance structural model displaying Mother-Internalizing Paths: Adolescent, mother, and father ratings combined.

Note. Asterisks label standardized parameter estimates for which $p<.05$. Disturbances and measurement error effects are omitted for clarity. 


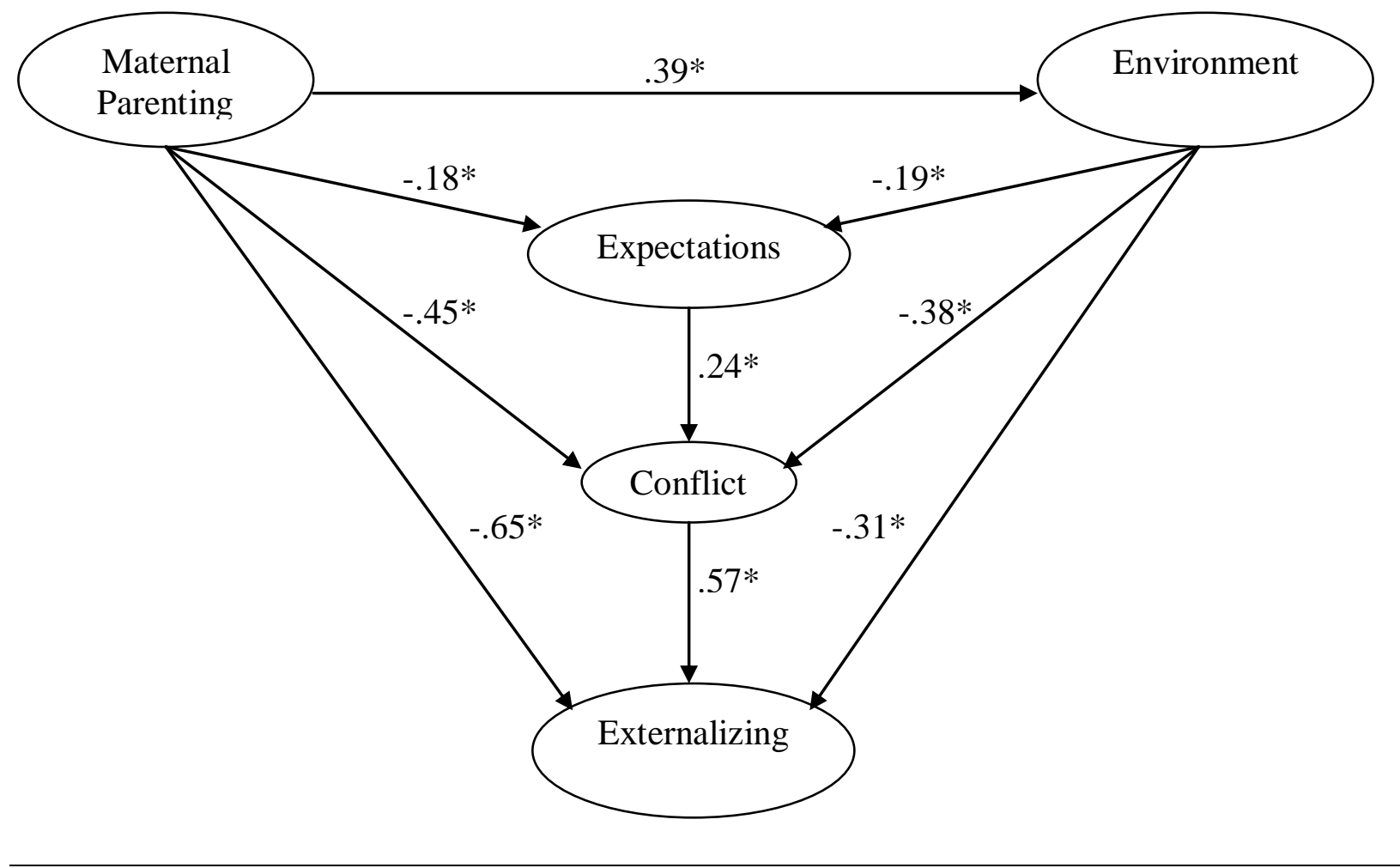

Figure 9: Male adolescent fitted covariance structural model displaying Mother-Externalizing Paths: Adolescent, mother, and father ratings combined.

Note. Asterisks label standardized parameter estimates for which $p<.05$. Disturbances and measurement error effects are omitted for clarity. 


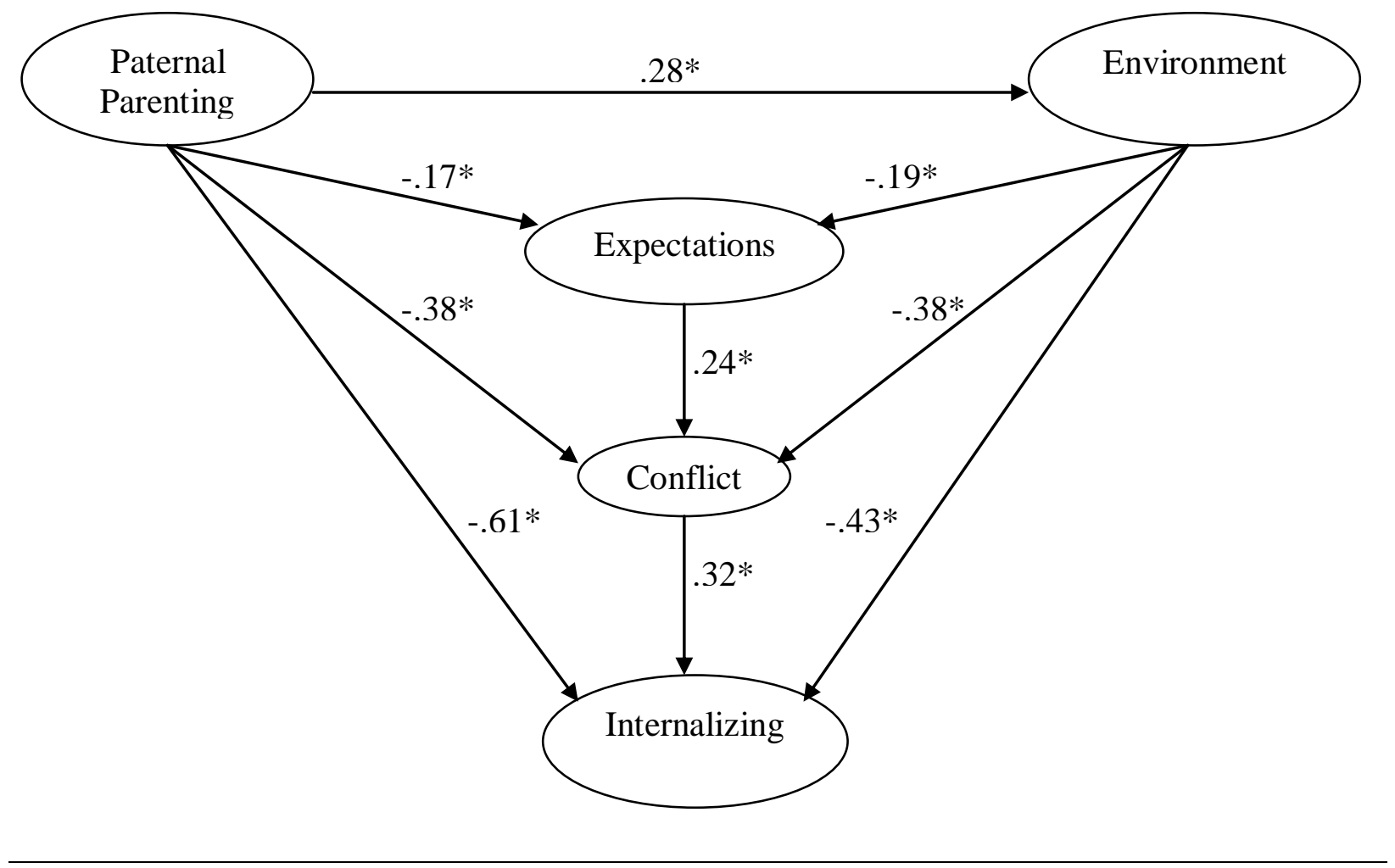

Figure 10: Male adolescent fitted covariance structural model displaying Father-Internalizing Paths: Adolescent, mother, and father ratings combined.

Note. Asterisks label standardized parameter estimates for which $p<.05$. Disturbances and measurement error effects are omitted for clarity. 


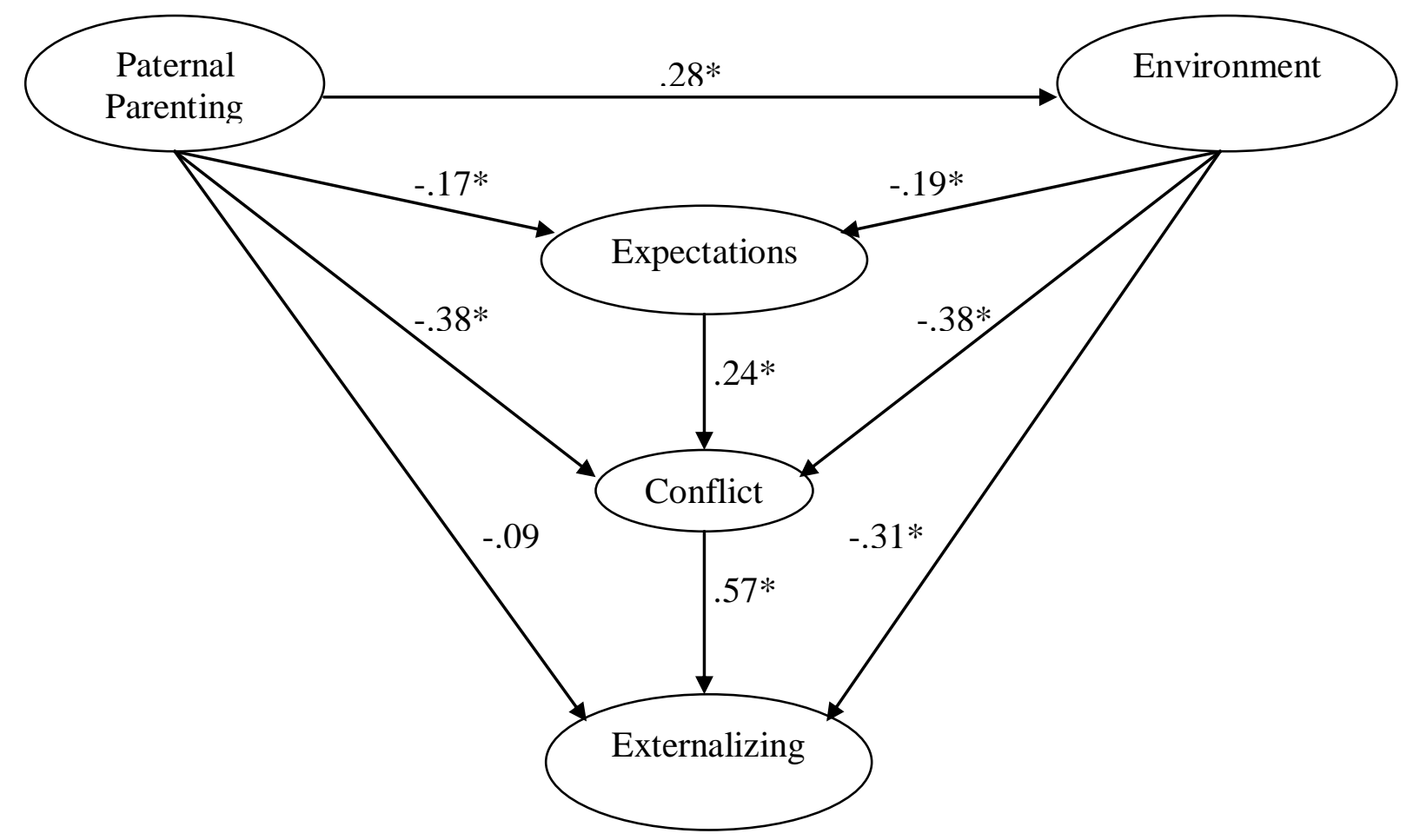

Figure 11: Male adolescent fitted covariance structural model displaying Father-Externalizing Paths: Adolescent, mother, and father ratings combined.

Note. Asterisks label standardized parameter estimates for which $p<.05$. Disturbances and measurement error effects are omitted for clarity. 


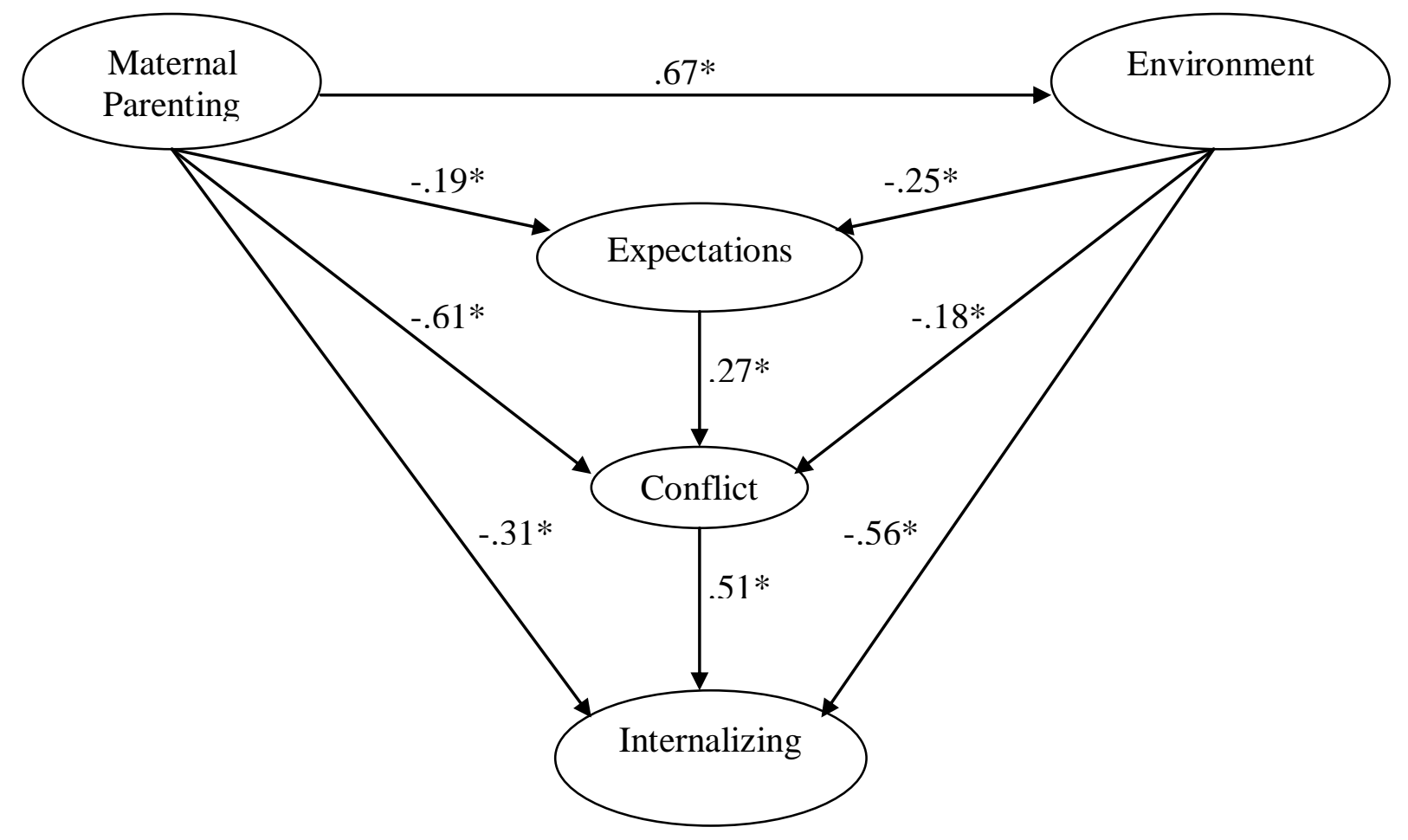

Figure 12: Female adolescent fitted covariance structural model displaying Mother-Internalizing Paths: Adolescent, mother, and father ratings combined.

Note. Asterisks label standardized parameter estimates for which $p<.05$. Disturbances and measurement error effects are omitted for clarity. 


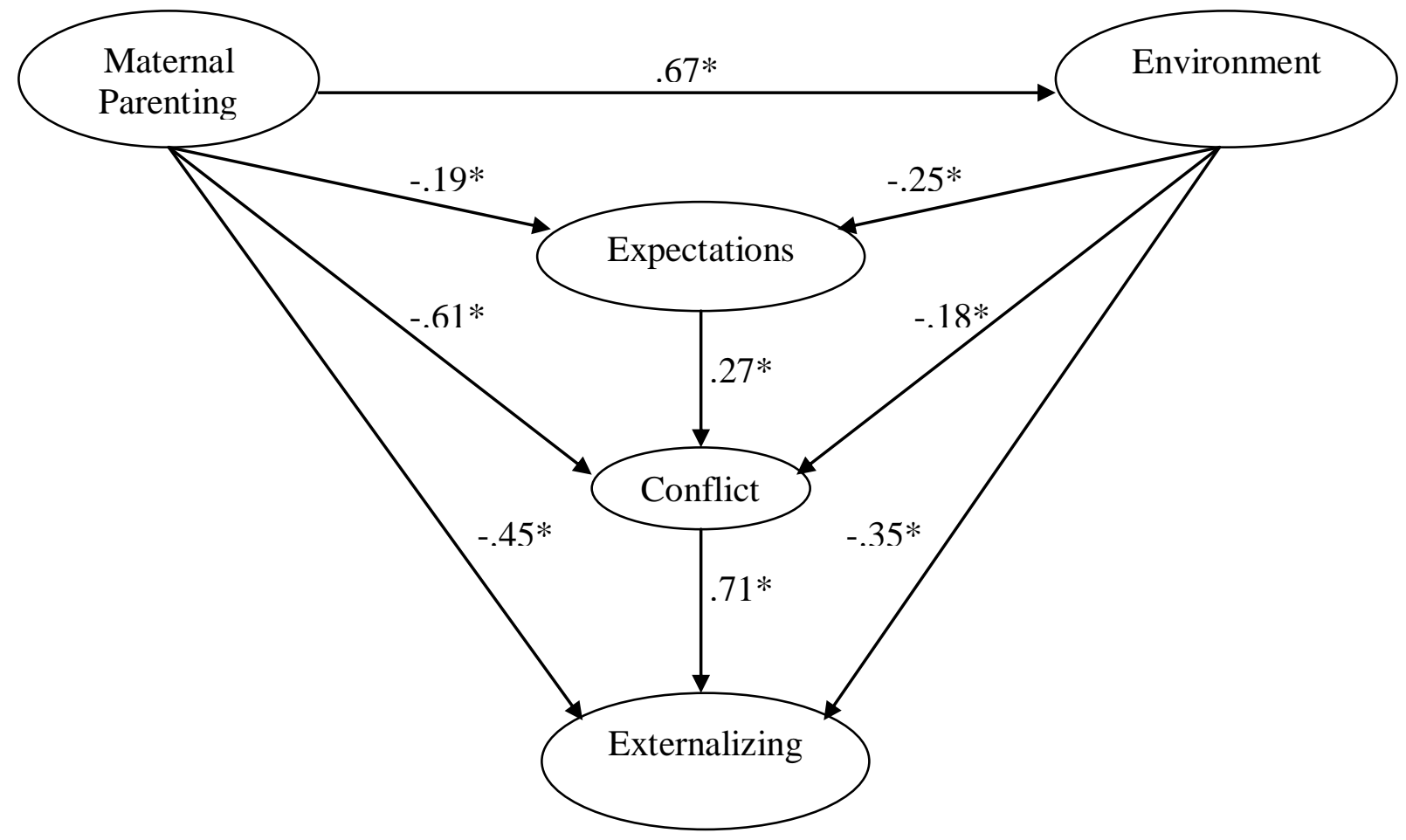

Figure 13: Female adolescent fitted covariance structural model displaying Mother-Externalizing Paths: Adolescent, mother, and father ratings combined.

Note. Asterisks label standardized parameter estimates for which $p<.05$. Disturbances and measurement error effects are omitted for clarity. 


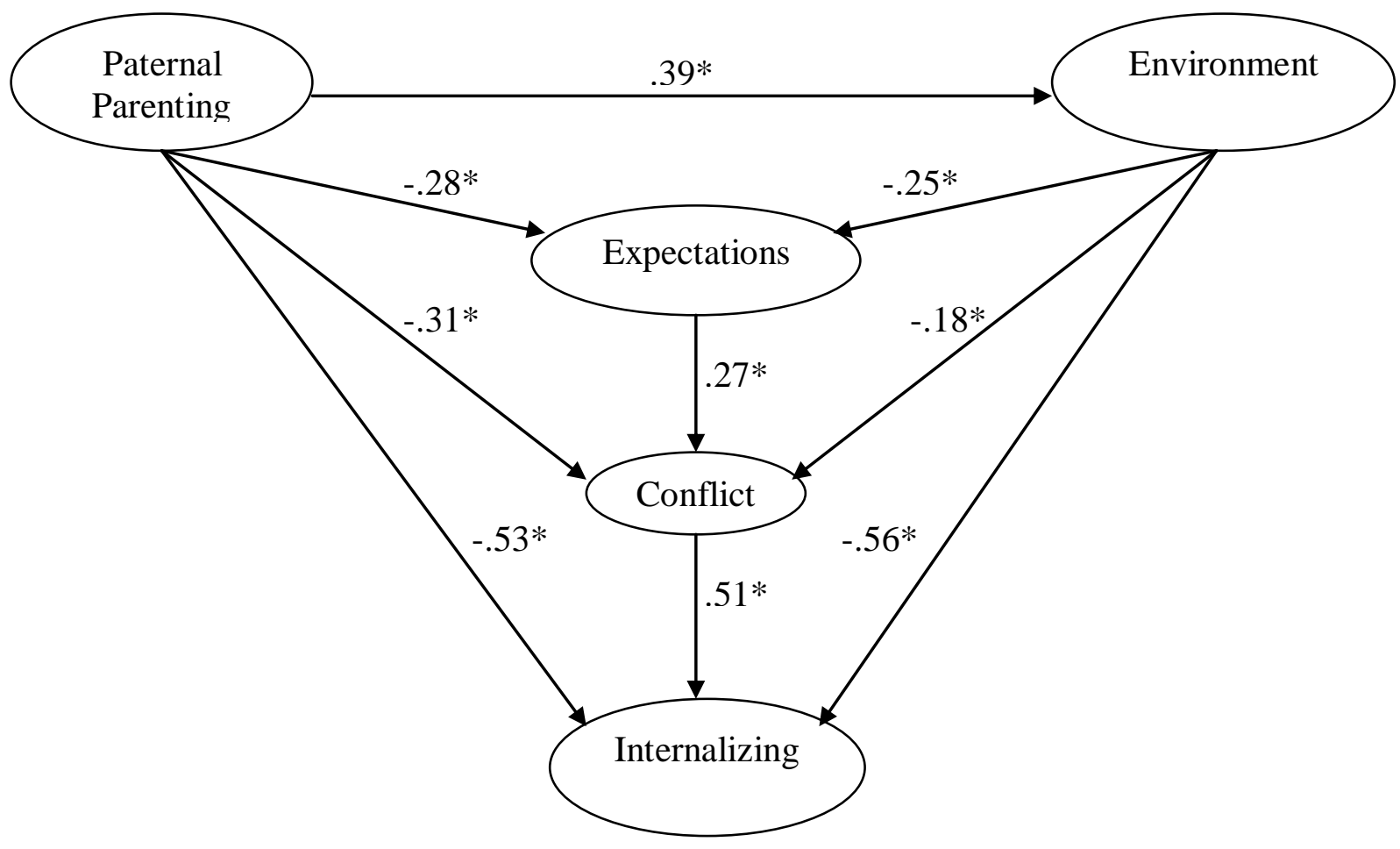

Figure 14: Female adolescent fitted covariance structural model displaying Father-Internalizing Paths: Adolescent, mother, and father ratings combined.

Note. Asterisks label standardized parameter estimates for which $p<.05$. Disturbances and measurement error effects are omitted for clarity. 


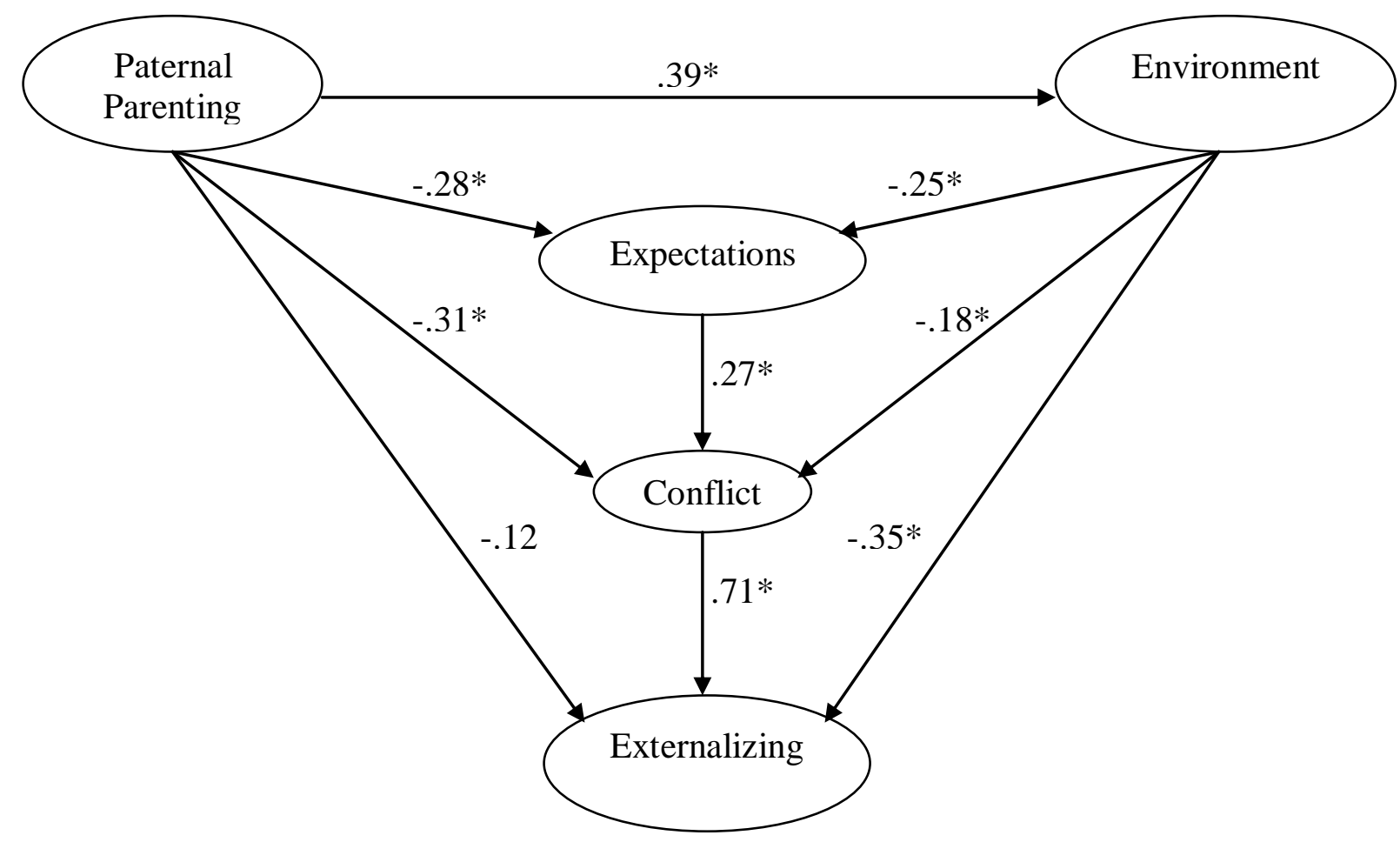

Figure 15: Female adolescent fitted covariance structural model displaying Father-Externalizing Paths: Adolescent, mother, and father ratings combined.

Note. Asterisks label standardized parameter estimates for which $p<.05$. Disturbances and measurement error effects are omitted for clarity. 


\section{Summary of Structural Equation Models}

Correlations among latent factors in the measurement models for mothers' ratings and fathers' ratings, as shown in Table 6 and 7, are consistent with each other as well as with correlations among latent factors for adolescents' ratings. Please see above for a description of the nature of these relationships, as they are similar to those discussed for the previously described models. Further, mothers' parenting and fathers' parenting are correlated moderately in a positive direction, and internalizing and externalizing behavior problems are correlated strongly in a positive direction.

According to the male and female structural models, internalizing behavior problems for male and female adolescents is predicted moderately to strongly by mothers' parenting, fathers' parenting, family environment, and conflict. These results fail to support Hypothesis 4 since parenting and family environment have a direct effect on internalizing behavior problems for male and female adolescents.

Externalizing behavior problems for male and female adolescents are predicted moderately to strongly by mothers' parenting, family environment, and conflict but are not significantly predicted by fathers' parenting. Hypothesis 4 is not supported when examining mothers' ratings since mothers' parenting has a direct effect on externalizing behavior problems for male and female adolescents. When examining fathers' ratings and externalizing behavior problems, however, Hypothesis 4 is supported. That is, the Paternal-Externalizing segments of the structural model for male and female adolescents support Hypothesis 4. For male and female adolescents, fathers' parenting no longer predicts externalizing behavior problems as it did when allowed to freely correlate. Instead, it continues to predict moderately conflict. Conflict, in turn, predicts moderately to strongly externalizing behavior problems in male and female adolescents. 


\section{CHAPTER FIVE: CONCLUSION}

\section{Goals of the Study}

The purpose of the current study is to investigate the multivariate effects of parenting, family environment, expectations, and conflict on early adolescent adjustment. With regard to the first goal of this study (i.e., to predict early adolescent adjustment given information pertaining to the parent-adolescent relationship variables examined in this study), these variables in relation to early adolescent adjustment are investigated as both measured and latent variables and with the use of adolescents', mothers', and fathers' reports. The correlational hypotheses (Hypotheses 1 through 3) of this study are supported across measured and latent variables for male and female adolescents' ratings and for mothers' and fathers' ratings.

Of the variables examined in this study, parenting demonstrates the highest correlations with adolescents' internalizing and externalizing behavior problems, followed closely by conflict and then family environment and expectations. These findings are consistent with previous research findings. In particular, warm and supportive parenting that is not high in control, cohesive and adaptable family environments, and levels of conflict that are not excessively high or intense all are related to fewer internalizing and externalizing behavior problems in early adolescence. Further, parenting, family environment, and expectations are correlated significantly with conflict (i.e., authoritative parenting, a cohesive and adaptable family environment, and earlier expectations are associated with lower levels of conflict). These findings lend support to individuation theory (Smetana, 2005), as parenting, family environment, and expectations may play important roles in how adolescents experience conflict within the parent-adolescent relationship. Specifically, supportive parenting in a cohesive and adaptable 
family environment contributes to resolving conflict and prevents issues from escalating (Rueter \& Conger, 1995). Further, parents who hold earlier expectations for their adolescents experience less conflict, as they expect their adolescents to take on more responsibility and autonomy sooner rather than later (Dekovic et al., 1997).

Overall, in this study, these relationships are similar across adolescents', mothers', and fathers' ratings and between measured and latent variables. Similar to previous studies (e.g., Epstein, Renk, Duhig, Bosco, \& Phares, 2004), parenting, family environment, expectations, conflict, and behavior problems share similar correlations across the various informants. Specifically, although some variation in the degree of relationships among these variables across raters exists, the significance and direction of each of the correlations are the same. Given the consistency of these findings across raters and between manifest variables and latent constructs, a fair amount of confidence may be placed in the relationships of these parent-adolescent relationship variables and early adolescent adjustment as described above. Thus, the first goal of this study is accomplished.

With regard to the second goal of this study (i.e., to pinpoint areas that are most critical to early adolescent outcomes), structural models are used to uncover the multivariate effects of parent-adolescent relationship variables. Hypothesis 4 (i.e., that there would not be direct relationships among parenting, family environment, and adolescents' internalizing and externalizing behavior problems) is not supported by the data using adolescents' ratings only. Parenting and family environment remain significant predictors when analyzed simultaneously in the structural model for both male and female adolescents, with parenting and conflict being strong predictors and family environment being a moderate to strong predictor of adjustment. Both the male and female adolescent models based on adolescents' ratings are similar, with the 
exception that parenting no longer predicts conflict in the female adolescent model. For female adolescents, parenting and conflict both predict adjustment, but parenting does not predict conflict as it does in the male adolescent model. It may be the case that male adolescents experience more conflict as a direct result of parenting than do female adolescents. For example, previous research suggests that males tend to experience more conflict over chores and everyday issues than females. In addition, females find their parenting relationships, particularly with mothers, to be more supportive and less conflictual than do males (Holmbeck et al., 1995). When examining adolescents' ratings in combination with mothers' and fathers' ratings, findings are largely consistent with data based on adolescents' ratings only. There are some exceptions, however. Similar to the adolescent only structural models, internalizing behavior problems for male and female adolescents are predicted moderately by mothers' and fathers' parenting, family environment, and conflict. Similarly, mothers' parenting, family environment, and conflict predict moderately to strongly externalizing behavior problems for both male and female adolescents. In contrast to the adolescent only models and lending support to Hypothesis 4, externalizing behavior problems for male and female adolescents are not predicted significantly by fathers' parenting when analyzed simultaneously in the structural model, even though a significant correlation exists in the measurement model. Conflict, in turn, predicts moderately to strongly externalizing behavior problems in male and female adolescents.

The finding noted above may be the most novel finding of the current study and is consistent with previous research showing that mothers' parenting, relative to fathers' parenting, is associated more strongly with adolescents' externalizing behavior problems (Kostas et al., 2008). In fact, Kostas and colleagues (2008) indicate that the quality of relationships with mothers, but not fathers, predicts adolescents' externalizing behavior problems over time. 
Further, Yahav (2006) reports that feeling rejected by mothers plays a central role in the development of externalizing behavior problems. Thus, it may be the case that mothers' parenting maintains a direct relationship with externalizing behavior problems in light of other constructs but that fathers' parenting does not.

Other explanations for this finding may be due to sex differences between mothers and fathers in their parenting. In this study and other studies, results indicate that fathers spend less time with their early adolescents when compared to mothers. Thus, the warmth and overprotection by these fathers may contribute less to the adjustment of adolescents than that of mothers, who spends more time caring for the adolescents. Instead, fathers remain important in resolving conflict and contributing to the family environment and thus influence adolescent adjustment through those pathways. These tendencies do not explain why the pathway is present for internalizing behavior problems and not externalizing behavior problems, however.

Alternatively, fathers may behave more instrumentally (i.e., fathers exhibit characteristics typically associated with masculinity, including independence, mastery, self-reliance, and assertiveness) with their early adolescents, whereas mothers may treat their adolescents with more expressiveness (i.e., mothers exhibit characteristics typically associated with femininity, including nurturance, interpersonal caring, sensitivity, and emotional openness). Thus, maternal parenting is related directly to adolescents' behavioral adjustment, as warmth is typically sought from the mother. In contrast, paternal parenting is related indirectly to adolescents' behavioral adjustment, as adolescents do not seek as much warmth from their fathers, who may provide other traditionally masculine characteristics, such as problem-solving, stability, and conflict resolution. 
Consistent with the prior explanation, it should be noted that fathers' parenting maintains a direct relationship with conflict, which is related directly to externalizing behavior problems. Thus, fathers' parenting remains just as significant a construct as mothers' parenting. Fathers' parenting, relative to mothers' parenting, may express its effects through different pathways, however, when considering the development of externalizing behavior problems in early adolescents.

Overall, the second goal of this study is accomplished. Specifically, the results of this study suggest that mothers' and fathers' parenting, family environment, and conflict all may be important points of intervention when dealing with early adolescents' internalizing behavior problems. Additionally, mothers' parenting, family environment, and conflict may be targeted for interventions addressing early adolescents' externalizing behavior problems. The models discussed in this study suggest that pinpointing these variables for intervention may have some effect when attempting to ameliorate early adolescents' internalizing and externalizing behavior problems. Further, multivariate analyses uncover a unique and most important finding in this study. Specifically, mothers' parenting and fathers' parenting both share powerful, but different, relationships with conflict and early adolescents' externalizing behavior problems. This finding suggests that other variables, such as conflict, must be considered simultaneously when investigating the effects of parenting on early adolescents' adjustment. Thus, it may be important for clinicians to understand that their interventions targeting traditional variables, such as parenting, may be working through indirect, rather than direct, pathways. As a result, in addition to examining more traditional variables, the variables involved in these indirect pathways also should be monitored as part of any interventions addressing adolescents' behavior problems. 
The third goal of this study (i.e., to integrate research concerning parent-adolescent relationship variables) also is accomplished. This study combines research on parenting with other variables (i.e., family environment, expectations, and conflict). Although many studies extensively test the effects of these variables in isolation, this study demonstrates that the relationship of these variables with early adolescent adjustment may change when examined simultaneously. Further, this study extends the model tested by McKinney and Renk (2008). As mentioned previously, key improvements to the prior model implemented in this study include examining internalizing and externalizing outcomes instead of only internalizing outcomes, incorporating parent data into the model for more reliable findings, and using a different measure of conflict that assesses more accurately conflict (i.e., as it is described by storm and stress and individuation theories). The prior model examined late adolescents and found multivariate and cross-sex effects not unlike those found in the current study. Overall, the model is improved upon and extended successfully to early adolescence. Further, both models demonstrate the need to consider multivariate effects as well as cross-sex effects.

Much work remains to be done in this area, however, as a plethora of variables remain to be incorporated into increasingly predictive and parsimonious models. Future studies should investigate additional variables that may influence adolescent development, such as marital discord, peer influences, and extracurricular activities, among other variables. Additionally, future studies should consider culturally diverse populations across childhood and adolescence so that the utility of models such as the one examined in this study can be explored during other developmental time periods. Further, future studies should examine families with different compositions, such as single-parent families, foster families, and non-traditional families. Whatever variables future studies research in adolescent development, it is suggested that 
variables be analyzed simultaneously rather than in isolation so that the intricate nature of parentadolescent relationships may be captured.

\section{Cross-Informant Ratings and Cross-Sex Effects}

Also emphasized by this study is the importance of obtaining cross-informant ratings. This study demonstrates similar and contrasting results when examining data based on adolescents' ratings only versus data based on adolescents', mothers', and fathers' ratings. Although many of the results are similar, the most novel finding of this study (i.e., the relationship of fathers' parenting, conflict, and early adolescents' externalizing behavior problems) is uncovered when examining cross-informant data. This finding would have been overlooked had this study relied solely on adolescents' report. Given possible differences in data from adolescent, mother, and father raters (e.g., Duhig, Renk, Epstein, \& Phares, 2000), obtaining multiple sources of data when investigating parent-adolescent relationships may be considered a prerequisite to acquiring reliable data (e.g., Renk, 2005). Thus, future studies in this area are encouraged to obtain not only cross-informant ratings but also other sources of data, such as interviews and behavioral observations, to increase the reliability of their findings.

Cross-sex effects also should be considered. Males and females differ significantly across several measures included in this study. Further, when using adolescents' ratings, the relationship of parenting and conflict in the female model is not significant, whereas this path is significant in the male model. When using adolescents' and parents' ratings, the relationship of fathers' parenting and adolescents' externalizing behavior problems is not direct. In contrast, the relationship of mothers' parenting and adolescents' externalizing behavior problems is direct when analyzed simultaneously in the structural models. Although many similarities among the models exist with regard to sex, subtle differences as described above indicate the importance of 
examining both male and female adolescent differences as well as maternal and paternal differences. These findings contribute to the extant literature cited above demonstrating the importance of considering cross-sex effects (Bosco et al., 2003; Eisenberg et al., 2008;

Holmbeck et al., 1995; Kostas et al., 2008; Lopez et al., 2008; McKinney \& Renk, 2008; Paulson \& Sputa, 1996; Moon \& Hoffman, 2008; Sim, 2003).

\section{Practical Implications}

The results presented in this study hold practical implications for researchers, clinicians, and even parents, teachers, and/or other individuals interested in adolescents' adjustment. For research, this study is consistent with the majority of the extant literature regarding the nature of the relationships among the variables that are examined here (Hypothesis 1 through 3). Perhaps more importantly, researchers must understand the necessity of collecting multiple sources of data and analyzing the data individually as well as simultaneously. Specifically in this study, different results are noted when adolescent ratings are examined along and when adolescent and parent ratings are examined collectively. Further, some of the relationships among the variables examined in this study differ in the correlation analyses relative to the structural models. Researchers must account for multiple sources of information as well as incorporate that information in a way that appreciates the processes involved.

Clinicians and other service providers also may find the results of this study to be informative. This study adds to the literature discussing variables that may be targeted to improve adjustment in early adolescents. For example, working with parents to increase their warmth, to create a cohesive and adaptive family environment, or to resolve conflict between themselves and their adolescents all may potentially lead to positive effects on early adolescents' internalizing and externalizing behavior problems. Further, this study emphasizes the importance 
of understanding the processes that are active in parent-adolescent relationships. Specifically, clinicians must consider how their interventions are working instead of merely being satisfied with a positive effect. Knowing the reasons that interventions work will help in their generalizability across clients and populations. For example, the correlations found in this study suggest that intervening with paternal parenting may lead to improvements in early adolescents' adjustment. As indicated in the structural models, however, the reason for this improvement may not be as direct as the case may be with other variables, such as maternal parenting, family environment, or conflict. Clinician and other service providers should consider these indirect relationships when developing valid case conceptualizations in the context of effective interventions.

Finally, many parents, teachers, and other caregivers search for resources in working with children and adolescents. This study may help these individuals understand the relationships among the variables discussed in this study. Further, parents and caregivers may be able to understand their early adolescent in light of the information presented in this study. For example, parents may be able to learn how they contribute to both positive and negative relationships with their early adolescents and begin to incorporate changes for both themselves and their adolescents in the context of their day-to-day living.

\section{$\underline{\text { Limitations }}$}

The findings of this study must be viewed in the context of its limitations. Regarding external validity, applying the results of this study to age groups other than early adolescence (i.e., 11- to 14-years old) must be done with caution. Also, all participants reported having a mother and father present in the home. Thus, the results of the study may not apply to singleparent homes, foster homes, or other types of living situations. Finally, the sample consisted 
solely of students who are attending a middle school in the central region of a Southeastern state. A strength of the study, however, may be the representative numbers of Hispanic, Caucasian, and African American participants, even though these groups are analyzed together since they did not differ significantly on the measures in this study. Another limitation of this study is that it relied solely on self-report. What adolescents and parents recollect of their experiences with each other may differ from what actually happens. Although this study attempted to overcome this shortcoming by obtaining cross-informant ratings, self-report carries inherent limitations. A third limitation of this study is its design. Correlational in nature, this study is unable to determine causation. In addition, parent-adolescent relationships encompass a wide array of variables, and this study may have overlooked important variables. Thus, many other factors not studied here may influence early adolescents' internalizing and externalizing behavior problems.

Other limitations are present in this study. First, the model presented here assumes conflict to be present, but other theories, such as harmonious parenting, may not be based on that assumption. Just as storm and stress and individuation theories do not account for a majority of adolescents, theories and models that do not consider conflict as central to development may be important to consider. Second, more information about familial characteristics may be helpful in generalizing the results of this study. For example, knowing how involved the other biological parent is in households with a stepparent would add important information to the study. Specifically, some participants in this study may think of themselves as having three or more caregivers based on their family composition. The level of involvement of these additional caregivers is not accounted for in this study. Third, considering variations of the model presented here may be worthwhile. For example, parenting may share a reciprocal relationship with family environment rather than a direct one. Specifically, the environmental characteristics present may 
contribute to warm or harsh parenting, just as warm or harsh parenting may create certain family environments. Fourth, handling the data differently for some variables may provide new information. Specifically, conflict was given a weighted score for the adolescent, mother figure, and father figure. A possible different way of handling this data would be to take a difference score between the conflict reported by adolescents and that reported by parents. A possible hypothesis could be that those with large difference scores experience more negative outcomes than those with small difference scores, regardless of the actual amount of conflict reported. Agreeing on the conflict may be more important than the actual amount of conflict experienced.

\section{Summary}

Overall, findings of the current study suggest that parenting, family environment, expectations, and conflict are related at varying levels to internalizing and externalizing behavior problems in early adolescents. This study also contributes to the literature emphasizing cross-sex effects in parent-adolescent relationships as well as the importance of obtaining cross-informant data. Finally, failing to consider a multivariate approach in the examination of these variables may result in limited findings or poor implementation of clinical interventions. For example, a unique finding (i.e., fathers' parenting and its relationship with adolescents' externalizing behavior problems) is not uncovered until data are tested with multivariate statistics. This finding is significant academically and clinically. Researchers must consider simultaneously a surfeit of variables to understand truly their direct and indirect effects. Likewise, clinicians must be careful to monitor such variables that may have direct and indirect effects on the outcomes with which they are concerned so that they may implement highly effective treatments based on valid case conceptualizations. 
APPENDIX A: DEMOGRAPHICS INFORMATION 


\section{Demographics: Adolescent Form}

Please complete each question to the best of your knowledge either by circling the appropriate answer or filling in the appropriate description. If an item is unclear, please ask the examiner for clarification.

1. Age:

2. Gender: Male Female

3. Race: Caucasian/White African American/Black Hispanic Asian Other: (Please describe)

4. Do you live in the same house as your father: Yes No

5. Do you live in the same house as your mother: Yes No

6. On average, how many hours per day do you spend with or talk to your father:

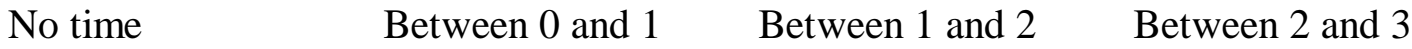

Between 3 and $4 \quad$ Between 4 and $5 \quad$ Between 5 and $6 \quad$ Between 6 and 7

Between 7 and $8 \quad$ Between 8 and $9 \quad$ Between 9 and $10 \quad$ Greater than 10

7. On average, how many hours per day do you spend with or talk to your mother:

No time Between 0 and $1 \quad$ Between 1 and $2 \quad$ Between 2 and 3

Between 3 and $4 \quad$ Between 4 and $5 \quad$ Between 5 and $6 \quad$ Between 6 and 7

Between 7 and $8 \quad$ Between 8 and $9 \quad$ Between 9 and $10 \quad$ Greater than 10

8. How many brothers do you have: __ Please give their ages:

9. How many sisters do you have: ___ Please give their ages:

10. Father's highest level of education:

Doctoral degree $\quad$ Masters degree Bachelor degree

Associates degree Highschool diploma/GED

If none of the above, please indicate highest grade completed:

11. Mother's highest level of education:

Doctoral degree Masters degree Bachelor degree

Associates degree Highschool diploma/GED

If none of the above, please indicate highest grade completed:

12. What is your father's job:

13. What is your mother's job: 


\section{Demographics: Parent Form}

Please complete each question to the best of your knowledge either by circling the appropriate answer or filling in the appropriate description. Please answer these questions regarding the child that participated in the study.

1. Age:

2. Gender: Male Female

3. Race: Caucasian/White African American/Black Hispanic Asian Other: (Please describe)

4. Do you live in the same house as your adolescent: Yes No

5. Do you live in the same house as your adolescent's other parent: Yes No

6. On average, how many hours per day do you spend with or talk to your adolescent:

$\begin{array}{llll}\text { No time } & \text { Between } 0 \text { and } 1 \quad \text { Between } 1 \text { and } 2 \quad \text { Between } 2 \text { and } 3\end{array}$

Between 3 and $4 \quad$ Between 4 and $5 \quad$ Between 5 and $6 \quad$ Between 6 and 7

Between 7 and $8 \quad$ Between 8 and $9 \quad$ Between 9 and $10 \quad$ Greater than 10

7. Your highest level of education:

Doctoral degree Masters degree Bachelor degree

Associates degree Highschool diploma/GED

If none of the above, please indicate highest grade completed:

8. Your spouse's highest level of education:

Doctoral degree Masters degree Bachelor degree

Associates degree Highschool diploma/GED

If none of the above, please indicate highest grade completed:

9. What is your job:

10. What is your spouse's job: 
APPENDIX B: PARENTAL BONDING INSTRUMENT 


\section{PBI: Adolescent Form}

Instructions: In this questionnaire, you will read statements about your parents. You will be asked to rate your Mother's and Father's behavior. For all questions, answer the statement as to how each parent acts toward you and circle your answer. If you are not living with your biological parents now, please rate whomever you consider to be your father or mother (e.g., adoptive parent, step-parent, etc.)

Very unlike

1
Moderately unlike 2
Moderately like 3
Very like 4

Please rate your Mother's and Father's behavior by circling your answer My mother

My father

1. Speaks to me with a warm and friendly voice

1234

1234

2. Does not help me as much as I need

1234

1234

3. Lets me do those things I like doing

1234

1234

4. Seems emotionally cold to me

1234

1234

5. Appears to understand my problems

1234

1234

6. Is affectionate to me

1234

1234

7. Likes me to make my own decisions

1234

1234

8. Does not want me to grow up

1234

1234

9. Tries to control everything I do

1234

1234

10. Invades my privacy

1234

1234

11. Enjoys talking things over with me

1234

1234

12. Frequently smiles at me

1234

1234

13. Tends to baby me

1234

1234

14. Does not seem to understand what I need or want

1234

1234

15. Lets me decide things for myself

1234

1234

16. Makes me feel I am wanted

1234

1234 
Very unlike

1
Moderately unlike 2
Moderately like

3
Very like 4

Please rate your Mother's and Father's behavior by circling your answer

My mother My father

17. Makes me feel better when I am upset

1234

1234

18. Does not talk with me very much

1234

1234

19. Tries to make me dependent on him/her

1234

1234

20. Feels I cannot look after myself unless he/she is around

1234

1234

21. Gives me as much freedom as I want

1234

1234

22. Lets me go out as often as I want

1234

1234

23. Is overprotective of me

1234

1234

24. Does not praise me

1234

1234

25 . Lets me dress in any way I please

1234 


\section{PBI: Parent Form}

Instructions: In this questionnaire, you will read statements about yourself. You will be asked to rate your own behavior. For all questions, answer the statement as to how you act toward your child who is participating in this study and circle your answer.

Very unlike

1
Moderately unlike 2
Moderately like 3
Very like 4

Please rate your own behavior toward your child by circling your answer

1. I speak to my child with a warm and friendly voice

1234

2. I do not help my child as much as he/she needs

1234

3. I let my child do those things he/she likes doing

1234

4. I seem emotionally cold to my child

1234

5. I appear to understand my child's problems

1234

6. I am affectionate to my child

1234

7. I like my child to make his/her own decisions

1234

8. I do not want my child to grow up

1234

9. I try to control everything my child does

1234

10. I invade my child's privacy

1234

11. I enjoy talking things over with my child

1234

12. I frequently smile at my child

1234

13. I tend to baby my child

1234

14. I do not seem to understand what my child needs or wants

1234

15. I let my child decide things for himself/herself

1234

16. I make my child feel he/she is wanted

1234

17. I make my child feel better when he/she is upset

1234

18. I do not talk with my child very much

1234

19. I try to make my child dependent on me

1234 
Please rate your own behavior toward your child by circling your answer

20. I feel my child cannot look after himself/herself unless I am around

21. I give my child as much freedom as he/she wants

22. I let my child go out as often as he/she wants

23. I am overprotective of my child

24. I do not praise my child

1234

25. I let my child dress in any way he/she pleases

1234 


\section{APPENDIX C: FAMILY ADAPTABILITY AND COHESION EVALUATION SCALE}


FACES-II

Instructions: In this questionnaire, you will read statements about the family the child lives with. You will be asked to rate your family's behavior. For all questions, answer the statement as to how your family acts and circle your answer.

\section{Almost Never Once in awhile Sometimes Frequently Almost Always 1

Please rate your family's behavior by circling your answer

1. Family members are supportive of each other during difficult times

12345

2. In our family, it is easy for everyone to express his/her opinion

12345

3. It is easier to discuss problems with people outside the family than with other

12345 family members

12345

4. Each family member has input regarding major family decisions

12345

5. Our family gathers together in the same room

12345

6. Children have a say in their discipline

12345

7. Our family does things together

12345

8. Family members discuss problems and feel good about the solutions

12345

9. In our family, everyone goes his/her own way

12345

10. We shift household responsibilities from person to person

12345

11. Family members know each other's close friends

12345

12. It is hard to know what the rules are in our family

12345

13. Family members may consult other family members on personal decisions

12345

14. Family members say what they want

12345

15. We have difficulty thinking of things to do as a family

12345

16. In solving problems, the children's suggestions are followed

12345

17. Family members feel very close to each other

12345 


\section{Almost Never Once in awhile Sometimes Frequently Almost Always

$12 \quad 3$ \\ 3

Please rate your family's behavior by circling your answer

18. Discipline is fair in our family

12345

19. Family members feel closer to people outside the family than to other family

12345 members

20. Our family tries new ways of dealing with problems

12345

21. Family members go along with what the family decides to do

12345

22. In our family, everyone shares responsibilities

12345

23. Family members like to spend their free time with each other

12345

24. It is difficult to get a rule changed in our family

12345

25. Family members avoid each other at home

12345

26. When problems arise, we compromise

12345

27. We approve of each other's friends

12345

28. Family members are afraid to say what is on their minds

12345

29. Family members pair up rather than do things as a total family

12345

30. Family members share interests and hobbies with each other

12345 
APPENDIX D: DEVELOPMENTAL TIMETABLES FOR ADOLESCENCE 
DTA: Adolescent Form

Instructions: In this questionnaire, you will read statements about your parents. You will be asked to rate your Mother's and Father's expectations. For all questions, answer the statement as to what each parent expects of you and circle your answer. If you are not living with your biological parents now, please rate whomever you consider to be your father or mother (e.g., adoptive parent, step-parent, etc.)

Please rate your Mother's and Father's expectations by circling your answer

At what age did/does your mother/father think you could/can...

1. Decide on your own curfew?

Mother: 8 or below $\quad 9-10 \quad 11-12 \quad 13-14 \quad 15-16 \quad 17-18 \quad 19-20 \quad 21-22 \quad 23-24 \quad 25$ or older

Father: 8 or below $\quad 9-10 \quad 11-12 \quad 13-14 \quad 15-16 \quad 17-18 \quad 19-20 \quad 21-22 \quad 23-24 \quad 25$ or older

2. Decide on what clothes you wear?

Mother: 8 or below $\quad 9-10 \quad 11-12 \quad 13-14 \quad 15-16 \quad 17-18 \quad 19-20 \quad 21-22 \quad 23-24 \quad 25$ or older

Father: 8 or below $\quad 9-10 \quad 11-12 \quad 13-14 \quad 15-16 \quad 17-18 \quad 19-20 \quad 21-22 \quad 23-24 \quad 25$ or older

3. Defend your own rights?

Mother: 8 or below $\quad 9-10 \quad 11-12 \quad 13-14 \quad 15-16 \quad 17-18 \quad 19-20 \quad 21-22 \quad 23-24 \quad 25$ or older

Father: 8 or below $\quad 9-10 \quad 11-12 \quad 13-14 \quad 15-16 \quad 17-18 \quad 19-20 \quad 21-22 \quad 23-24 \quad 25$ or older

4. Go to a disco or café alone or with friends?

Mother: 8 or below $\quad 9-10 \quad 11-12 \quad 13-14 \quad 15-16 \quad 17-18 \quad 19-20 \quad 21-22 \quad 23-24 \quad 25$ or older

Father: 8 or below $\quad 9-10 \quad 11-12 \quad 13-14 \quad 15-16 \quad 17-18 \quad 19-20 \quad 21-22 \quad 23-24 \quad 25$ or older

5. Handle your own money?

Mother: 8 or below $\quad 9-10 \quad 11-12 \quad 13-14 \quad 15-16 \quad 17-18 \quad 19-20 \quad 21-22 \quad 23-24 \quad 25$ or older

Father: 8 or below $\quad 9-10 \quad 11-12 \quad 13-14 \quad 15-16 \quad 17-18 \quad 19-20 \quad 21-22 \quad 23-24 \quad 25$ or older

6. Spend a vacation without parents or another adult?

Mother: 8 or below $\quad 9-10 \quad 11-12 \quad 13-14 \quad 15-16 \quad 17-18 \quad 19-20 \quad 21-22 \quad 23-24 \quad 25$ or older

Father: 8 or below $\quad 9-10 \quad 11-12 \quad 13-14 \quad 15-16 \quad 17-18 \quad 19-20 \quad 21-22 \quad 23-24 \quad 25$ or older

7. Go alone to a doctor?

Mother: 8 or below $\quad 9-10 \quad 11-12 \quad 13-14 \quad 15-16 \quad 17-18 \quad 19-20 \quad 21-22 \quad 23-24 \quad 25$ or older

Father: 8 or below $\quad 9-10 \quad 11-12 \quad 13-14 \quad 15-16 \quad 17-18 \quad 19-20 \quad 21-22 \quad 23-24 \quad 25$ or older

8. Stay home alone when parents are away for a weekend?

Mother: 8 or below $\quad 9-10 \quad 11-12 \quad 13-14 \quad 15-16 \quad 17-18 \quad 19-20 \quad 21-22 \quad 23-24 \quad 25$ or older

Father: 8 or below $\quad 9-10 \quad 11-12 \quad 13-14 \quad 15-16 \quad 17-18 \quad 19-20 \quad 21-22 \quad 23-24 \quad 25$ or older 
Please rate your Mother's and Father's expectations by circling your answer

At what age did/does your mother/father think you could/can...

9. Accept your body changes?

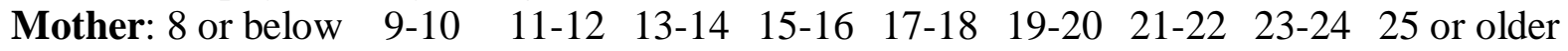

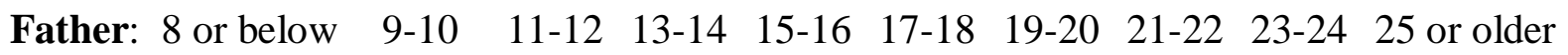

10. Be aware of your own strengths and weaknesses?

Mother: 8 or below $9-10 \quad 11-12 \quad 13-14 \quad 15-16 \quad 17-18 \quad 19-20 \quad 21-22 \quad 23-24 \quad 25$ or older

Father: 8 or below $\quad 9-10 \quad 11-12 \quad 13-14 \quad 15-16 \quad 17-18 \quad 19-20 \quad 21-22 \quad 23-24 \quad 25$ or older

11. Take account of another's judgment regarding oneself?

Mother: 8 or below $\quad 9-10 \quad 11-12 \quad 13-14 \quad 15-16 \quad 17-18 \quad 19-20 \quad 21-22 \quad 23-24 \quad 25$ or older

Father: 8 or below $\quad 9-10 \quad 11-12 \quad 13-14 \quad 15-16 \quad 17-18$ 19-20 $21-22 \quad 23-24 \quad 25$ or older

12. Have an opinion or preference regarding political parties?

Mother: 8 or below $\quad 9-10 \quad 11-12 \quad 13-14 \quad 15-16 \quad 17-18 \quad 19-20 \quad 21-22 \quad 23-24 \quad 25$ or older

Father: 8 or below $\quad 9-10 \quad 11-12 \quad 13-14 \quad 15-16 \quad 17-18 \quad 19-20 \quad 21-22 \quad 23-24 \quad 25$ or older

13. Choose your own life philosophy or religion?

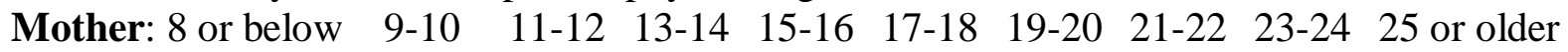

Father: 8 or below $\quad 9-10 \quad 11-12 \quad 13-14 \quad 15-16 \quad 17-18 \quad 19-20 \quad 21-22 \quad 23-24 \quad 25$ or older

14. Have an opinion regarding social issues such as abortion, death penalty, etc.?

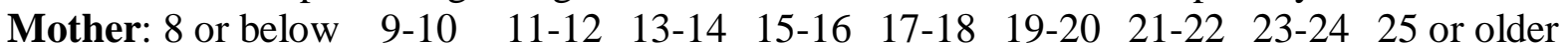

Father: 8 or below $\quad 9-10 \quad 11-12 \quad 13-14 \quad 15-16 \quad 17-18 \quad 19-20 \quad 21-22 \quad 23-24 \quad 25$ or older

15. Have a steady group of friends?

Mother: 8 or below $9-10 \quad 11-12 \quad 13-14 \quad 15-16 \quad 17-18 \quad 19-20 \quad 21-22 \quad 23-24 \quad 25$ or older

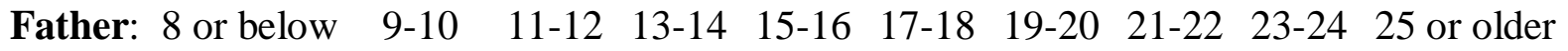

16. Have a best friend?

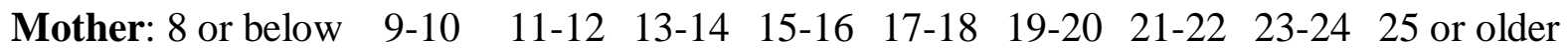

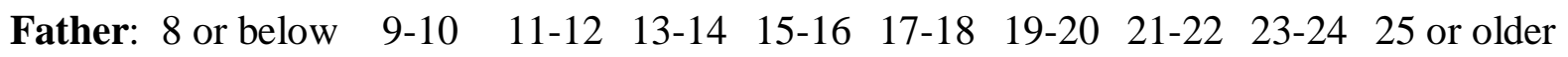

17. Have a boyfriend/girlfriend?

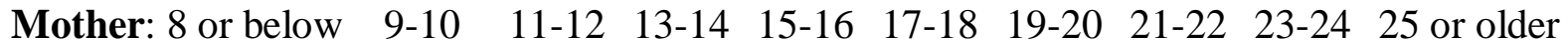

Father: 8 or below $\quad 9-10 \quad 11-12 \quad 13-14 \quad 15-16 \quad 17-18 \quad 19-20 \quad 21-22 \quad 23-24 \quad 25$ or older

18. Be involved in a sexual relationship?

Mother: 8 or below $\quad 9-10 \quad 11-12 \quad 13-14 \quad 15-16 \quad 17-18 \quad 19-20 \quad 21-22 \quad 23-24 \quad 25$ or older

Father: 8 or below $\quad 9-10 \quad 11-12 \quad 13-14 \quad 15-16 \quad 17-18 \quad 19-20 \quad 21-22 \quad 23-24 \quad 25$ or older

19. Bear responsibility for successfully completing school?

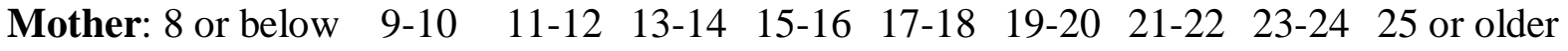

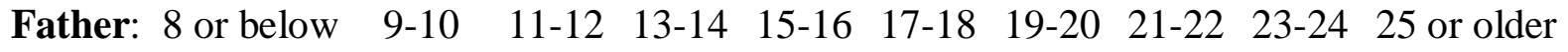


Please rate your Mother's and Father's expectations by circling your answer

At what age did/does your mother/father think you could/can...

20. Choose a profession?

Mother: 8 or below $\quad 9-10 \quad 11-12 \quad 13-14 \quad 15-16 \quad 17-18 \quad 19-20 \quad 21-22 \quad 23-24 \quad 25$ or older

Father: 8 or below $\quad 9-10 \quad 11-12 \quad 13-14 \quad 15-16 \quad 17-18 \quad 19-20 \quad 21-22 \quad 23-24 \quad 25$ or older

21. Choose a job?

Mother: 8 or below $\quad 9-10 \quad 11-12 \quad 13-14 \quad 15-16 \quad 17-18 \quad 19-20 \quad 21-22 \quad 23-24 \quad 25$ or older

Father: 8 or below $\quad 9-10 \quad 11-12 \quad 13-14 \quad 15-16 \quad 17-18 \quad 19-20 \quad 21-22 \quad 23-24 \quad 25$ or older

22. Be financially independent?

Mother: 8 or below $\quad 9-10 \quad 11-12 \quad 13-14 \quad 15-16 \quad 17-18 \quad 19-20 \quad 21-22 \quad 23-24 \quad 25$ or older

Father: 8 or below $\quad 9-10 \quad 11-12 \quad 13-14 \quad 15-16 \quad 17-18 \quad 19-20 \quad 21-22 \quad 23-24 \quad 25$ or older

23. Live on your own?

Mother: 8 or below $\quad 9-10 \quad 11-12 \quad 13-14 \quad 15-16 \quad 17-18 \quad 19-20 \quad 21-22 \quad 23-24 \quad 25$ or older

Father: 8 or below $\quad 9-10 \quad 11-12 \quad 13-14 \quad 15-16 \quad 17-18 \quad 19-20 \quad 21-22 \quad 23-24 \quad 25$ or older

24. Have your own family and take care of them?

Mother: 8 or below $\quad 9-10 \quad 11-12 \quad 13-14 \quad 15-16 \quad 17-18 \quad 19-20 \quad 21-22 \quad 23-24 \quad 25$ or older

Father: 8 or below $\quad 9-10 \quad 11-12 \quad 13-14 \quad 15-16 \quad 17-18 \quad 19-20 \quad 21-22 \quad 23-24 \quad 25$ or older 


\section{DTA: Parent Form}

Instructions: In this questionnaire, you will read statements about yourself. You will be asked to rate your own expectations. For all questions, answer the statement as to what you expect of your child who is participating in this study and circle your answer.

Please rate your own expectations of your child by circling your answer

At what age did/do you think your child could/can...

1. Decide on his/her own curfew?

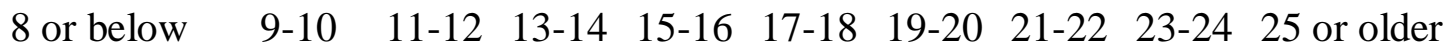

2. Decide on what clothes he/she wears?

8 or below $\quad 9-10 \quad 11-12 \quad 13-14 \quad 15-16 \quad 17-18 \quad 19-20 \quad 21-22 \quad 23-24 \quad 25$ or older

3. Defend his/her own rights?

$\begin{array}{lllllllll}8 \text { or below } \quad 9-10 & 11-12 & 13-14 & 15-16 & 17-18 & 19-20 & 21-22 & 23-24 & 25 \\ \text { or older }\end{array}$

4. Go to a disco or café alone or with friends?

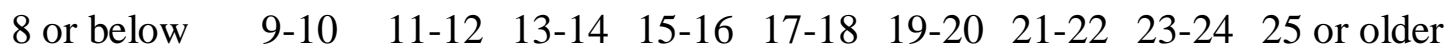

5. Handle his/her own money?

8 or below $\quad 9-10 \quad 11-12 \quad 13-14 \quad 15-16 \quad 17-18 \quad 19-20 \quad 21-22 \quad 23-24 \quad 25$ or older

6. Spend a vacation without parents or another adult?

8 or below $\quad 9-10 \quad 11-12 \quad 13-14 \quad 15-16 \quad 17-18 \quad 19-20 \quad 21-22 \quad 23-24 \quad 25$ or older

7. Go alone to a doctor?

8 or below $\quad 9-10 \quad 11-12 \quad 13-14 \quad 15-16 \quad 17-18 \quad 19-20 \quad 21-22 \quad 23-24 \quad 25$ or older

8. Stay home alone when parents are away for a weekend?

8 or below $\quad 9-10 \quad 11-12 \quad 13-14 \quad 15-16 \quad 17-18 \quad 19-20 \quad 21-22 \quad 23-24 \quad 25$ or older

9. Accept his/her body changes?

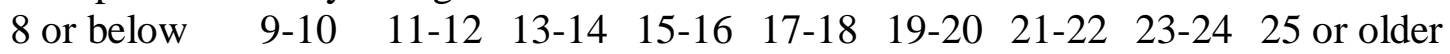

10. Be aware of his/her own strengths and weaknesses?

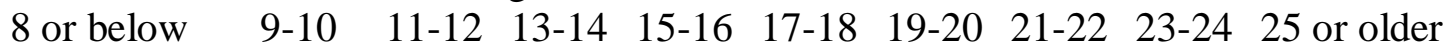

11. Take account of another's judgment regarding himself/herself?

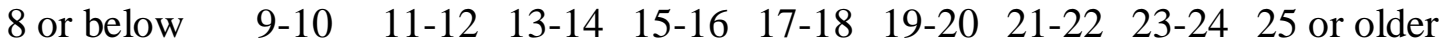

12. Have an opinion or preference regarding political parties?

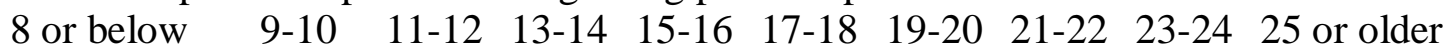

13. Choose his/her own life philosophy or religion?

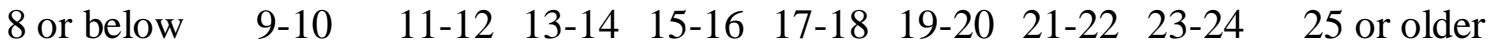


Please rate your own expectations of your child by circling your answer

At what age did/do you think your child could/can...

14. Have an opinion regarding social issues such as abortion, death penalty, etc.?

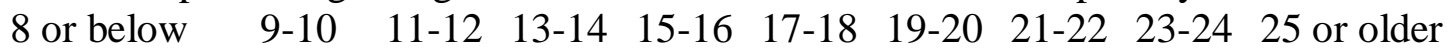

15. Have a steady group of friends?

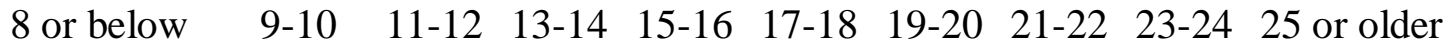

16. Have a best friend?

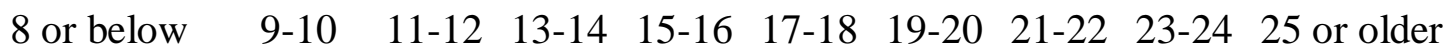

17. Have a boyfriend/girlfriend?

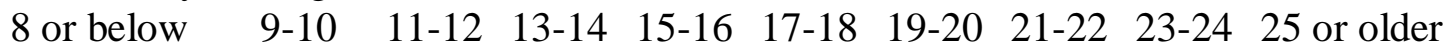

18. Be involved in a sexual relationship?

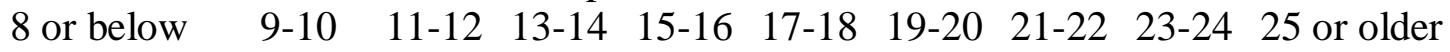

19. Bear responsibility for successfully completing school?

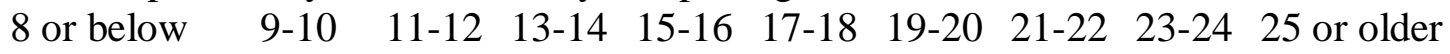

20. Choose a profession?

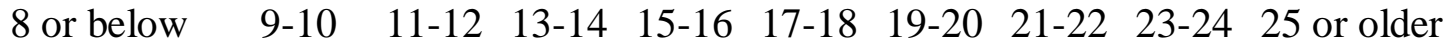

21. Choose a job?

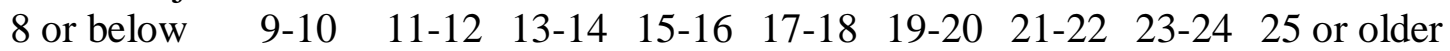

22. Be financially independent?

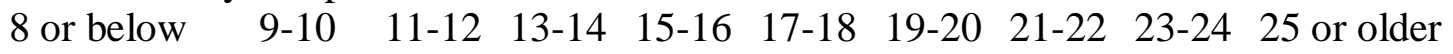

23. Live on his/her own?

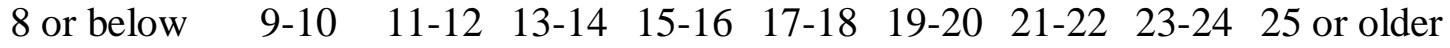

24. Have his/her own family and take care of them?

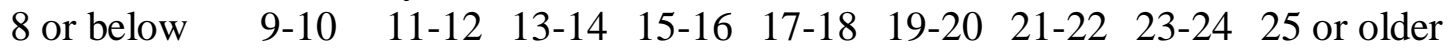


APPENDIX E: ISSUES CHECKLIST 
IC

Instructions: Below is a list of things that sometimes get talked about at home. Circle YES for the topics that you and your parents/son or daughter have talked about at all during the last 4 weeks. Circle NO for those that have not come up. For those topics that you circled YES, answer the following 2 questions. How many times during the last 4 weeks has it come up? (Give a number). How hot are the discussions for each topic?

Have you discussed?

1. Telephone calls

2. Time for going to bed

3. Cleaning up bedroom

4. Doing homework

5. Putting away clothes

6. Using the television

7. Cleanliness (washing, showers, brushing teeth)

8. Which clothes to wear

9. How neat clothing looks

10. Making too much noise at home

11. Table manners

12. Fighting with brothers and sisters

13. Cursing

14. How money is spent

15. Picking books or movies

16. Allowance
How many times? Calm A little angry Angry

Yes No

Yes No

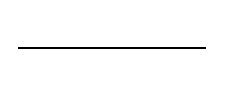

Yes No

Yes No

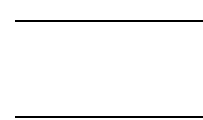

Yes No

Yes No

Yes No
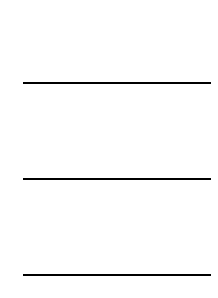

Yes No

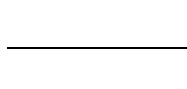

Yes No

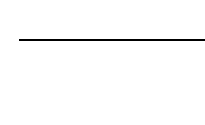

Yes No

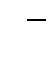

Yes No

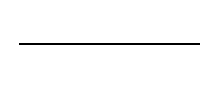

Yes No

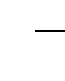

Yes No

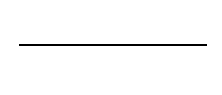

Yes No

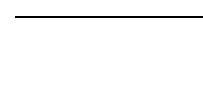

Yes No

Yes No

$\begin{array}{lllll}1 & 2 & 3 & 4 & 5 \\ 1 & 2 & 3 & 4 & 5 \\ 1 & 2 & 3 & 4 & 5 \\ 1 & 2 & 3 & 4 & 5 \\ 1 & 2 & 3 & 4 & 5 \\ 1 & 2 & 3 & 4 & 5\end{array}$

$\begin{array}{lllll}1 & 2 & 3 & 4 & 5\end{array}$

$\begin{array}{lllll}1 & 2 & 3 & 4 & 5\end{array}$

$\begin{array}{lllll}1 & 2 & 3 & 4 & 5\end{array}$

$\begin{array}{lllll}1 & 2 & 3 & 4 & 5\end{array}$

$\begin{array}{lllll}1 & 2 & 3 & 4 & 5\end{array}$

$\begin{array}{lllll}1 & 2 & 3 & 4 & 5\end{array}$

$\begin{array}{lllll}1 & 2 & 3 & 4 & 5\end{array}$

$\begin{array}{lllll}1 & 2 & 3 & 4 & 5\end{array}$

$\begin{array}{lllll}1 & 2 & 3 & 4 & 5\end{array}$ 
Have you discussed?

17. Going places without parents (shopping, movies)

18. Playing stereo or radio too Yes No loudly

19. Turning off lights in the Yes No house

20. Drugs

21. Taking care of records, games, bikes, pets, and other things

22. Drinking beer or other liquor

23. Buying records, games, Yes No toys, and things

24. Going on dates

25. Who should be friends

26. Selecting new clothes

27. Sex

28. Coming home on time

29. Getting to school on time

30. Getting low grades in school Yes No

31. Getting in trouble at school Yes No

32. Lying

33. Helping out around the house

34. Talking back to parents

Yes No

35. Getting up in the morning Yes No
How many times? Calm A little angry Angry

$\begin{array}{lllll}1 & 2 & 3 & 4 & 5\end{array}$

$$
\begin{array}{lllll}
1 & 2 & 3 & 4 & 5
\end{array}
$$

$\begin{array}{lllll}1 & 2 & 3 & 4 & 5\end{array}$

$\begin{array}{lllll}1 & 2 & 3 & 4 & 5\end{array}$

$\begin{array}{lllll}1 & 2 & 3 & 4 & 5\end{array}$

$\begin{array}{lllll}1 & 2 & 3 & 4 & 5\end{array}$

$\begin{array}{lllll}1 & 2 & 3 & 4 & 5\end{array}$

$\begin{array}{lllll}1 & 2 & 3 & 4 & 5\end{array}$

$\begin{array}{lllll}1 & 2 & 3 & 4 & 5\end{array}$

$\begin{array}{lllll}1 & 2 & 3 & 4 & 5\end{array}$

$\begin{array}{lllll}1 & 2 & 3 & 4 & 5\end{array}$

$\begin{array}{lllll}1 & 2 & 3 & 4 & 5\end{array}$

$\begin{array}{lllll}1 & 2 & 3 & 4 & 5\end{array}$

$\begin{array}{lllll}1 & 2 & 3 & 4 & 5\end{array}$

$\begin{array}{lllll}1 & 2 & 3 & 4 & 5\end{array}$

$\begin{array}{lllll}1 & 2 & 3 & 4 & 5\end{array}$

$\begin{array}{lllll}1 & 2 & 3 & 4 & 5\end{array}$

$\begin{array}{lllll}1 & 2 & 3 & 4 & 5\end{array}$

$\begin{array}{lllll}1 & 2 & 3 & 4 & 5\end{array}$ 
Have you discussed?

How many times? Calm A little angry Angry

36. Bothering parents when they Yes No want to be left alone

37. Bothering teenager when Yes No he/she wants to be left alone

38. Putting feet on furniture

$$
\text { Yes No }
$$

$\begin{array}{lllll}1 & 2 & 3 & 4 & 5\end{array}$

39. Messing up the house

Yes No

$\begin{array}{lllll}1 & 2 & 3 & 4 & 5\end{array}$

40. What time to have meals

Yes No

$\begin{array}{lllll}1 & 2 & 3 & 4 & 5\end{array}$

41. How to spend free time

Yes No

$\begin{array}{lllll}1 & 2 & 3 & 4 & 5\end{array}$

42. Smoking

Yes No

1

2

$\begin{array}{lllll}1 & 2 & 3 & 4 & 5\end{array}$

43. Earning money away

from the house

Yes No

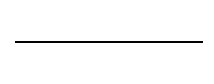

1

44. What teenager eats

Yes No

$\begin{array}{lllll}1 & 2 & 3 & 4 & 5\end{array}$


APPENDIX F: YOUTH SELF-REPORT/CHILD BEHAVIOR CHECKLIST 
Sample Items from the YSR/CBCL

Below are sample items from the Youth Self Report and Child Behavior Checklist. Items between the measures correspond generally with wording changes to reflect the participant (e.g., your child argues a lot versus I argue a lot). Participants rate items as "Not True," "Somewhat or Sometimes True," or "Very True or Often True."

Sample items loading onto Externalizing Behavior Problems

1. I argue a lot

2. I disobey at school

3. I break rules at home, school, or elsewhere

4. I get in many fights

5. I run away from home

6. I steal at home

7. I am mean to others

8. I destroy my own things

Sample items loading onto Internalizing Behavior Problems

1. There is very little that I enjoy

2. I feel that I have to be perfect

3. I feel lonely

4. I am nervous or tense

5. I repeat certain acts over and over

6. My moods or feelings change suddenly

7. I am unhappy, sad, or depressed

8. I worry a lot 
APPENDIX G: INFORMED CONSENT FORM 


\section{CONSENT FORM FOR PARENT PARTICIPATION}

Please review this form with your experimenter and sign the back side if you agree with the terms presented here.

PROJECT: A Multivariate Model of Parent-Adolescent Interaction Variables in Early and Middle Adolescence.

INVESTIGATORS: Cliff McKinney, M.S., and Kim Renk, Ph.D. CONTACT: Kim Renk, Ph.D., Department of Psychology, HPH 409G, 407-823-2218,krenk@pegasus.cc.ucf.edu

You are being asked to participate in a project conducted through the Psychology Department at the University of Central Florida. A basic description of the purpose of the project, the procedures to be used, and the potential benefits and risks of participation are provided below. Please read this explanation carefully, and ask any questions prior to signing the form. If you choose to participate, please sign and date this form.

The information obtained in this study will be used to evaluate relationships among parent-adolescent interaction variables and their impact on current functioning. Your responses will be kept strictly confidential and stored in a locked file cabinet belonging to the Faculty Investigator listed above. Your name will only appear on this consent form, which will be detached from your packet of questionnaires and stored in a separate location from your packet of questionnaires. The packet of questionnaires you will complete will in no way be associated with your name.

By completing this questionnaire, you will be able to learn first-hand what it is like to participate in a research study. You will also be able to further your understanding about the relationship between parent-adolescent interaction variables and different experiences adults may have. Although there are no known risks for participating in this study, some participants may be sensitive to material contained in the questionnaires. Should you have an emotional reaction to the material presented in the session, please notify the experimenter in your session or the faculty investigator listed on this form. Your participation is completely voluntary, and you have the right to withdraw at any time during the study without penalty. Further, you do not have to answer any question you do not wish to answer. For participating, you may receive one hour of extra credit. You will be provided with a debriefing form following the completion of your questionnaire packet.

If you believe you have been injured during participation in this research project, you may file a claim with UCF Environmental Health \& Safety, Risk and Insurance Office, P.O. Box 163500, Orlando, FL 32816-3500 (407) 823-6300. The University of Central Florida is an agency of the State of Florida for purposes of sovereign immunity and the university's and the state's liability for personal injury or property damage is extremely limited under Florida law. Accordingly, the university's and the state's ability to compensate you for any personal injury or property damage suffered during this research project is very limited. 
Information regarding your rights as a research volunteer may be obtained from:

Barbara Ward

Institutional Review Board (IRB)

University of Central Florida

12443 Research Parkway, Suite 207

Orlando, Florida 32826-3252

Telephone: (407) 823-2901

I acknowledge that the benefits and risks involved in this research study have been fully explained to me, and I have been informed that I may withdraw form participation at any time without penalty.

$\mathrm{I}$, (PRINT NAME), state that I am at least 18 years of age and that I agree to participate freely and voluntarily in this research study.

Signature of Participant

Signature of Investigator
Date

Date 
APPENDIX H: PERMISSION FORM 


\title{
PARENTAL PERMISSION FORM FOR CHILD PARTICIPATION
}

\author{
PROJECT: Parent-Adolescent Relationships in Early and Middle Adolescence \\ INVESTIGATORS: Cliff McKinney, M.S., \& Kimberly Renk, Ph.D. \\ CONTACT: Kimberly Renk, Ph.D., 407-823-2218 \\ University of Central Florida, Department of Psychology, \\ P.O. Box 161390, Orlando, FL 32816
}

You are being asked to allow your child to participate in a project conducted through the Psychology Department at the University of Central Florida. The purpose of the project, the ways it will be performed, and the possible benefits and risks of participation are provided below. Please read this explanation carefully, and contact us with any questions prior to signing the form. If you then choose to allow your child to participate, please sign and date this form.

Along with this form, you are being asked to complete a survey packet your relationship with your child. Your child will be asked to fill out a similar packet of surveys. For example, the forms ask questions about your child's parenting, expectations, and adjustment. The information will be collected during one regular school hour. The team of researchers and assistants will visit your child's classroom, and a packet will be given to each child whose parent has already provided permission for their participation. Please note that this project has been approved by the Institutional Review Board at the University of Central Florida, your child's school district, your child's school principal, and your child's teacher. Your consent is also required for your child's participation, however, you are not required to allow your child to participate.

All responses will be kept strictly confidential, which means that no one will see them except for the researchers. Also, your name and your child's name only will be on this consent form, which will be separated from the surveys. This means that all responses will be entirely anonymous. The surveys you and your child will be completing will be labeled with a number only, and they will be stored in a locked filing cabinet in the locked psychology laboratory of the investigators listed above at the University of Central Florida.

By filling out the surveys, your child will learn what it is like to participate in a research project. The information from this study will help us learn more about the thoughts and feelings of children of many ethnic backgrounds. If your child has negative feelings about any of the surveys during the session, he/she will be able to talk to the investigator or the faculty investigator listed on this form. Your child's participation is voluntary, which means that he/she may stop at any time during the project without any consequence. 
Information regarding your parental rights and your child's rights as research volunteers may be obtained from:

\author{
Barbara Ward \\ Institutional Review Board (IRB) \\ University of Central Florida \\ 12443 Research Parkway, Suite 207 \\ Orlando, Florida 32826-3252
}

Telephone: (407) 823-2901

If you believe you have been injured during participation in this research project, you may file a claim with UCF Environmental Health \& Safety, Risk and Insurance Office, P.O. Box 163500, Orlando, FL 32816-3500 (407) 823-6300. The University of Central Florida is an agency of the State of Florida for purposes of sovereign immunity and the university's and the state's liability for personal injury or property damage is extremely limited under Florida law. Accordingly, the university's and the state's ability to compensate you for any personal injury or property damage suffered during this research project is very limited.

I acknowledge that the benefits and risks involved in this research study have been fully explained to me, and I have been informed that I or my child may withdraw from participation at any time without penalty.

$\mathrm{I}$, (PRINT NAME), state that I am at least 18 years of age and that I agree to allow my child to participate freely and voluntarily in this research project.

\begin{tabular}{lc}
\hline Parent Signature & Date \\
\hline Parent Signature & Date \\
\hline Name of Your Child (PLEASE PRINT)
\end{tabular}

\begin{tabular}{|l}
\hline $\begin{array}{l}\text { I, } \\
\text { do NOT agree to allow my }\end{array}$ \\
participate in this research project. \\
\\
\hline Parent Signature \\
\hline
\end{tabular}


APPENDIX I: ASSENT FORM 


\begin{abstract}
ASSENT FORM
PROJECT: Parent-Adolescent Relationship Variables in Early and Middle Adolescence INVESTIGATORS: Cliff McKinney, M.S. \& Kimberly Renk, Ph.D.

CONTACT: Kimberly Renk, Ph.D., 407-823-2218

University of Central Florida, Department of Psychology,

P.O. Box 161390, Orlando, FL 32816
\end{abstract}

Please READ this explanation carefully, and ASK any QUESTIONS before signing.

You are being asked to participate in a research study. You will be asked to complete some surveys about your parents. Your responses will be kept completely confidential, which means that your name will be separated from your answers. No one but the researchers will see your responses, so please try to answer honestly. The information will provide valuable knowledge about all different kinds of young people, like yourself. If you become uncomfortable at any time, please tell the researcher immediately. Your participation in this project is completely voluntary, and YOU MAY STOP AT ANY TIME.

I acknowledge that the benefits and risks involved in this research study have been fully explained to me, and I have been informed that I may withdraw from participation at any time without penalty.

$\mathrm{I}$, freely and voluntarily in this research project.

(PRINT NAME), state that I agree to participate

Signature of Participant

Signature of Investigator
Date

Date 


\section{APPENDIX J: FACILITY CONSENT FORM}




\title{
FACILITY APPROVAL FORM
}

\author{
PROJECT: A Multivariate Model of Parent-Adolescent Relationship Variables \\ in Early and Middle Adolescence \\ INVESTIGATORS: Kimberly Renk, Ph.D., and Cliff McKinney, M.S., graduate student
}

Below is a brief description of a research project being conducted through the Psychology Department at the University of Central Florida. The purpose of the project and the proposed method of data collection are provided. If you agree to allow the researchers to attempt to conduct such research with the teacher(s) and students of your facility, please sign and date this form.

Project Overview. The investigators noted above from the Department of Psychology at the University of Central Florida are studying the relationships between certain parental and family characteristics and current child adjustment. The purpose of this study is to gain a better understanding of various family characteristics and the psychological well-being of children. Not only will this information add to the current literature, but it will help to guide the development of evidence-based interventions tailored to the needs of families raising children.

Facility Recruitment. The Institutional Review Board (IRB) of the University of Central Florida and the review committee for your school district have provided approval for conduction of the research project entitled "A Multivariate Model of Parent-Adolescent Relationship Variables in Early and Middle Adolescence." No schools will be required to participate despite previous school board approval; therefore, each principal will retain the option to refuse participation. Once approval has been obtained from principals, teachers then will be contacted to request participation in the study.

Participant Recruitment. We are seeking a subject pool of 100-200 families, including parents (minimum 18 years of age) and their children. No compensation will be given for participation. Parent participants who do not receive the parent packet of questionnaires directly from one of the investigators or via postal mail will receive it in the following manner. Instructors who agree to participate will be provided with parent questionnaire packets to be handed out to each child at the end of a class period. Each child (regardless of racial or ethnic background) will have the opportunity to participate by taking home the parent packets for their parent(s) to complete. These forms will be returned by the student directly to their instructor, who then will be asked to mail the forms to the investigators in self-addressed, stamped envelopes prepared in advance for them (or they will be collected by the investigators in person). Collection of the parent packets will take place over the course of three weeks (starting on the date they are dispersed to the classes) to allow sufficient time for the parents to complete the forms and for children to return them to their instructors. Parent consent must be obtained from one legal guardian for a child to be eligible for individual participation. Child participation will take place by one of the following two methods. Some child participants who have received parent permission will receive the child questionnaire packets directly from their instructor to be taken home, completed, and returned to their instructor. For other students, the investigators will arrange dates with individual instructors to allow a research team to attend their class to administer questionnaire packets to those students whose parents have consented to their participation. Children whose parents have not consented to participation will be provided with an alternative activity during the data collection session. Depending upon the number of students in each class who have provided parental consent and constraints dictated by individual facility 
administrations, the child participants may remain in the classroom during participation, or they may be asked to leave the classroom to attend a brief data collection session in a large auditorium or lunchroom area. All complete child questionnaire packets will be collected directly by the investigators at each facility. We believe that there will be no more than minimal risk to children should they participate in this study. Please note that a potential "minimal" risk is indicated above because some children may be more self-conscious about rating their own emotions and behaviors whereas other children will not experience any type of self-conscious response.

Participation is completely voluntary. All information will be kept strictly confidential, with only a code number appearing on the collected information so that forms can be grouped by family (i.e., parent and child packets from the same family will be matched). Family identities will be kept confidential to the extent provided by law. All information gathered will be examined statistically within a group format, not individually. No individual information will be shared with local agencies or facilities unless a particular child's parent specifically requests it in writing. Information regarding participants' rights as research volunteers may be obtained from Barbara Ward, Institutional Review Board (IRB), University of Central Florida, 12443 Research Parkway, Suite 207, Orlando, FL 32826-3252 (Telephone: (407) 823-2901).

I have discussed the parameters of this research study with the experimenter, and I agree to allow the researchers to approach teachers in this facility to request their participation.

Facility Name

Facility Official Date

(Signature \& Position)

Principal Investigator Date

Kimberly Renk, Ph.D. Date

Principal Investigator and Supervisor 
APPENDIX K: DEBRIEFING FORM 


\section{A Multivariate Model of Parent-Adolescent Interaction Variables in Early and Middle Adolescence}

Thank you for participating in this research study. This study was conducted so that we may find out more about relationships among parent-adolescent interaction variables and their impact on current functioning. In particular, we are interested in the characteristics of the parentadolescent relationship that impact current functioning.

In your packet, you completed questionnaires regarding the characteristics of your relationship with your parents or child, your family, and current functioning. These responses will be used to examine the relationships among these variables using correlational and regression analyses.

In general, it has been found that the parent-adolescent relationship is complex and may be related to several factors. In particular, the types of interactions that parents and adolescents have may be involved in the development of positive or negative outcomes for adolescents. Any parent-adolescent interaction characteristics that may be potentially related to current functioning should be considered when examining the relationship of parent-adolescent interaction variables to an individual's current functioning.

If you would like more information about parent-adolescent interactions and their impact on current functioning, please refer to the following sources:

Baumrind, D. (1991). Effective parenting during the early adolescent transition. In P. A. Cowan (Ed.), Family transitions (pp. 111-163). Hillsdale, NJ: Lawrence Erlbaum Associates.

Collins, W. A. (1990). Parent-child relationships in the transition to adolescence: Continuity and change in interaction, affect, and cognition. In R. Monetemayor, G. Adams, \& T. Gullotta (Eds.), Advances in adolescent development: From childhood to adolescence: A transitional period? (Vol. 2, pp. 85-106). Beverly Hills, CA: Sage.

Grotevant, H. D., \& Cooper, C. R. (1986). Individuation in family relationships. Human Development, 29, 83-100.

Holmbeck, G. N. (1996). A model of family relational transformations during the transition to adolescence: Parent-adolescent conflict and adaptation. In J. A. Graber \& J. Brooks-Gunn (Eds.), Transitions through adolescence: Interpersonal domains and context (pp. 167199). Hillsdale, NJ: Lawrence Erlbaum Associates.

If you have any further questions about this research study, please contact Kim Renk, Ph.D., by phone (407-823-2218) or e-mail (krenk@pegasus.cc.ucf.edu). 
APPENDIX L: COVER LETTER 


\section{To Whom It May Concern:}

You are receiving this packet because your child's school has agreed to participate in a research study investigating factors related to parent-child relationships. Your participation in this study is voluntary and anonymous. The information you provide, however, will be helpful in providing information about parent-child relationships.

You will find the following materials within this packet:

1) A Consent Form for you to sign should you choose to participate

2) A Permission Form for you to sign should you choose to allow your child to participate

3) Parent Packet (one for yourself and one for your spouse, if applicable)

4) Debriefing Form explaining some details of the study

5) An Assent Form for your child to sign if he/she is able to participate

6) Child Packet

If you choose to participate, please sign the Consent Form and complete the set of measures contained in the Parent Packet. If applicable, ask your child's other parent to also participate. If you choose to allow your child to participate, please sign the Permission Form. If you grant permission for your child to participate, your child will complete similar measures at his/her school.

Once materials have been completed, please allow your child to return completed materials to his/her teacher at school. Even if you choose not to participate, please allow your child to return the blank packets to his/her teacher so that valuable materials will not be wasted.

Once packets are received by the investigator, forms with identifying information will be removed from the packet to ensure anonymity. Thank you for your time and consideration to participate in this study. 
APPENDIX M: INSTITIONAL REVIEW BOARD APPROVAL 
April 11, 2006

Kimberly Renk, Ph.D. and

Cliff McKinney

University of Central Florida

Department of Psychology

PH 409G

Orlando, FL 32816-1390

Dear Dr. Renk and Mr. McKinney:

With reference to your protocol \#06-3418 entitled, "A Multivariate Model of ParentAdolescent Relationship.Variables in Early and Middle Adolescence," I am enclosing for your records the approved, expedited document of the UCF IRB Protocol Submission Form you had submitted to our office. $\times$ This study was approved on 4/6/06. The expiration date will be $4 / 5 / 07$. Should there be a need to extend this study, a Continuing Review form must be submitted to the IRB Office for review by the Chairman or full IRB at least one month prior to the expiration date. This is the responsibility of the investigator. Please notify the IRB office when you have completed this research study.

Please be advised that this approval is given for one year. Should there be any addendums or administrative changes to the already approved protocol, they must also be submitted to the Board through use of the Addendum/Modification Request form. Changes should not be initiated until written IRB approval is received. Adverse events and unanticipated problems should be reported to the IRB as they occur.

Should you have any questions, please do not hesitate to call me at 407-823-2901.

Please accept our best wishes for the success of your endeavors.

Cordially,

Banbara Ward

Barbara Ward, CIM

UCF IRB Coordinator

(FWA00000351 Exp. 5/13/07, IRB00001138)

Copies: IRB File

BW:jm 


\section{LIST OF REFERENCES}

Achenbach, T. M., \& Rescorla, L.A. (2001). Manual for the ASEBA school-age forms \& profiles. Burlington, VT: University of Vermont, Research Center for Children, Youth, \& Families.

Anderson, J. C., \& Gerbing, D. W. (1988). Structural equations modeling in practice: A review and recommended two-step approach. Psychological Bulletin, 103, 411-423.

Arnett, J. J. (1999). Adolescent storm and stress, reconsidered. American Psychologist, 54, 317-326.

Baumrind, D. (1991). Effective parenting during the early adolescent transition. In P. A. Cowan (Ed.), Family transitions (pp. 111-163). Hillsdale, NJ: Lawrence Erlbaum Associates.

Bentler, P. M. (1992). On the fit of models to covariances and methodology to the Bulletin. Psychological Bulletin, 112, 400-404.

Bianchi, S. M., Robinson, J. P., \& Milkie, M. A. (2006). Changing rhythms of American family life. New York, NY: Russell Sage Foundation.

Bosco, G. L., Renk, K., Dinger, T. M., Epstein, M. K., \& Phares, V. (2003). The connections between adolescents' perceptions of parents, parental psychological symptoms, and adolescent functioning. Journal of Applied Developmental Psychology, 24, 179-200.

Brooks-Gunn, J., \& Zahaykevich, M. (1989). Parent-daughter relationships in early adolescence: A developmental perspective. In K. Kreppner \& R. M. Lerner (Eds.), Family systems and life-span development (pp. 223-246). Hillsdale, NJ: Lawrence Erlbaum Associates. 
Crean, H. F. (2008). Conflict in the Latino parent-youth dyad: The role of emotional support from the opposite parent. Journal of Family Psychology, 22, 484-493.

Collins, W. A., \& Luebker, C. (1994). Parent and adolescent expectancies: Individual and relational significance. In J. G. Smetana (Ed.), Beliefs about parenting: Origins and developmental implications (pp. 65-80). San Francisco, CA: Jossey-Bass/Pfeiffer.

Comstock, J. (1994). Parent-adolescent conflict: A developmental approach. Western Journal of Communication, 58, 263-282.

Dekovic, M. (1999). Parent-adolescent conflict: Possible determinants and consequences. International Journal of Behavioral Development, 23, 977-1000.

Dekovic, M., Noom, M. J., \& Meeus, W. (1997). Expectations regarding development during adolescence: Parental and adolescent perceptions. Journal of Youth and Adolescence, 26, 253-272.

Demo, D. H., Small, S. A., \& Savin-Williams, R. C. (1987). Family relations and the selfesteem of adolescents and their parents. Journal of Marriage and the Family, 49, 705715.

Duhig, A. M., Renk, K., Epstein, M. K., \& Phares, V. (2000). Interparental agreement on internalizing, externalizing, and total behavior problems: A meta-analysis. Clinical Psychology: Science and Practice, 7, 435-453.

Eisenberg, N., Hofer, C., Spinrad, T. L., Gershoff, E. T., Valiente, C., Losoya, S. H., Zhou, Q., Cumberland, A., Liew, J., Reiser, M., \& Maxon, E. (2008). Understanding motheradolescent conflict discussions: Concurrent and across-time prediction from youths' dispositions and parenting. Monographs of the Society for Research in Child Development, 73, 1-160. 
Epstein, M. K., Renk, K., Duhig, A. M., Bosco, G. L., \& Phares, V. (2004). Interparental conflict, adolescent behavioral problems, and adolescent competence: Convergent and discriminant validity. Educational and Psychological Measurement, 64, 475-495.

Freud, A. (1968). Adolescence. In A. E. Winder \& D. Angus (Eds.), Adolescence: Contemporary studies (pp. 13-24). New York: American Book.

Grotevant, H. D., \& Cooper, C. R. (1986). Individuation in family relationships. Human Development, 29, 83-100.

Gunlicks-Stoessel, M. L., \& Powers, S. I. (2008). Adolescents' emotional experiences of motheradolescent conflict predict internalizing and externalizing symptoms. Journal of Research on Adolescence, 18, 621-642.

Hall, G. S. (1904). Adolescence: Its psychology and its relations to physiology, anthropology, sociology, sex, crime, religion, and education (Vols. I \& II). Englewood Cliffs, NJ: Prentice-Hall.

Henderson, C. E., Dakof, G. A., Schwartz, S. J., \& Liddle, H. A. (2006). Family functioning, self-concept, and severity of adolescent externalizing problems. Journal of Child and Family Studies, 15, 721-731.

Hofer, M., Youniss, J., \& Noack, P. (1998). Verbal interaction and development in families with adolescents. In M. Hofer, J. Youniss, \& P. Noack (Eds.), Verbal interaction and development in families with adolescents (pp. 1-10). Westport, CT: Ablex Publishing. Holmbeck, G. N. (1996). A model of family relational transformations during the transition to adolescence: Parent-adolescent conflict and adaptation. In J. A. Graber \& J. Brooks-Gunn (Eds.), Transitions through adolescence: Interpersonal domains and context (pp. 167199). Hillsdale, NJ: Lawrence Erlbaum Associates. 
Holmbeck, G. N., Paikoff, R. L., \& Brooks-Gunn, J. (1995). Parenting adolescents. In M. H. Bornstein (Ed.), Handbook of parenting (pp. 91-118). Mahwah, NJ: Lawrence Erlbaum Associates.

James, L. R., Mulaik, S. S., \& Brett, J. M. (1982). Causal analysis: Assumptions, models, and data. Beverly Hills, CA: Sage Publications.

Kline, R. B. (1998). Principles and practice of structural equation modeling. New York, NY: The Guilford Press.

Kostas, A. F., Henrick, C. C., Brookmeyer, K. A., \& Kuperminc, G. P. (2008). Toward a transactional model of parent-adolescent relationship quality and adolescent psychological adjustment. Journal of Early Adolescence, 28, 252-276.

Kotchick, B. A., \& Forehand, R. (2002). Putting parenting in perspective: A discussion of contextual factors that shape parenting practices. Journal of Child and Family Studies, $11,255-269$.

Krappman, L., Schuster, B., \& Youniss, J. (1998). Can mothers win? The transformation of mother-daughter relationships in late childhood. In M. Hofer, J. Youniss, \& P. Noack (Eds.), Verbal interaction and development in families with adolescents (pp. 11-29). Westport, CT: Ablex Publishing.

Laursen, B., \& Collins, W. A. (1994). Interpersonal conflict during adolescence. Psychological Bulletin, 115, 197-209.

Laursen, B., \& Collins, W. A. (2004). Parent-child communication during adolescence. In A. L. Vangelisti (Ed.), Handbook of family communication (pp. 333-348). Mahwah, NJ: Lawrence Erlbaum Associates. 
Lopez, E. E., Perez, S. M., Ochoa, G. M., \& Ruiz, D. M. (2008). Adolescent aggression: Effects of gender and family and school environments. Journal of Adolescence, 31, 433-450.

Maccoby, E. E., \& Martin, J. A. (1983). Socialization in the context of the family: Parent-child interaction. In P. H. Mussen \& E. M. Hetherington (Eds.), Handbook of child psychology: Socialization, personality, and social development (Vol. 4, pp. 1-101). New York: Wiley.

McKinney, C., \& Renk, K. (2008). Multivariate models of parent-late adolescent gender dyads: The importance of underlying processes in predicting emotional adjustment. Child Psychiatry and Human Development, 39, 147-170.

McLaughlin, K. A., Hilt, L. M., \& Nolan-Hoeksema. (2007). Racial/ethnic differences in internalizing and externalizing symptoms in adolescents. Journal of Abnormal Child Psychology, 35, 801-816.

Moon, M., \& Hoffman, C. D. (2008). Mothers' and fathers' differential expectancies and behaviors: Parent x child gender effects. The Journal of Genetic Psychology, 164, 261279.

Noack, P., \& Kracke, B. (1998). Continuity and change in family interactions across adolescence. In M. Hofer, J. Youniss, \& P. Noack (Eds.), Verbal interaction and development in families with adolescents (pp. 65-81). Westport, CT: Ablex Publishing.

Noack, P., \& Puschner, B. (1999). Differential trajectories of parent-child relationships and psychosocial adjustment in adolescents. Journal of Adolescence, 22, 795-804.

Noom, M., \& Dekovic, M. (1998). Family interaction as a context for the development of adolescent autonomy. In M. Hofer, J. Youniss, \& P. Noack (Eds.), Verbal interaction and development in families with adolescents (pp. 109-125). Westport, CT: Ablex Publishing. 
Olson, D. H., Bell, R., \& Portner, J. (1992). Family inventories manual. Minneapolis, MN: Life Innovations.

Paikoff, R. L., \& Brooks-Gunn, J. (1991). Do parent-child relationships change during puberty? Psychological Bulletin, 110, 47-66.

Parker, G., Tupling, H., \& Brown, L. B. (1979). A parental bonding instrument. British Journal of Medical Psychology, 52, 1-10.

Paulson, S. E., \& Sputa, C. L. (1996). Patterns of parenting during adolescence: Perceptions of adolescents and parents. Adolescence, 31, 369-381.

Paulussen-Hoogeboom, M. C., Stams, G. J. J. M., Hermanns, J. M. A., Peetsma, T. T. D., \& Wittenboer, G. L. H. (2008). Parenting style as a mediator between children's negative emotionality and problematic behavior in early childhood. The Journal of Genetic Psychology, 169, 209-226.

Prinz, R. J., Foster, S. L., Kent, R. N., \& O’Leary, K. D. (1979). Multivariate assessment of conflict in distressed and non-distressed mother-adolescent dyads. Journal of Applied Behavior Analysis, 12, 691-700.

Renk, K. (2005). Cross-informant ratings of the behavior of children and adolescents: The "gold standard". Journal of Child and Family Studies, 14, 457-468.

Renk, K., Liljequist, L., Simpson, J., \& Phares, V. (2005). Gender and age differences in the topics of parent-adolescent conflict. The Family Journal, 13, 139-149.

Robin A. L., \& Foster S. L. (1989). Negotiating parent-adolescent conflict: A behavioral-family systems approach. New York, NY: Guilford Press. 
Ross, R. D., Marrinan, S., Schattner, S., \& Gullone, E. (1999). The relationship between perceived family environment and psychological wellbeing: Mother, father, and adolescent reports. Australian Psychologist, 34, 58-63.

Rueter, M. A., \& Conger, R. D. (1995). Antecedents of parent-adolescent disagreements. Journal of Marriage and Family, 57, 435-448.

Scabini, E. (2000). Parent-child relationships in Italian families: Connectedness and autonomy in the transition to adulthood. Psicologia: Teoria e Pesquisa, 16, 023-030.

Sim, T. N. (2003). The father-adolescent relationship in the context of the mother-adolescent relationship: Exploring moderating linkages in a late-adolescent sample in Singapore. Journal of Adolescent Research, 18, 383-404.

Smetana, J. G. (1995). Conflict and coordination in adolescent-parent relationships. In S. Shulman (Ed.), Close relationships and socioemotional development (pp. 128-154). Westport, CT: Ablex Publishing.

Smetana, J. G. (1996). Adolescent-parent conflict: Implications for adaptive and maladaptive development. In D. Cicchetti \& S. L. Toth (Eds.), Adolescence: Opportunities and challenges (pp. 1-46). Rochester, NY: University of Rochester Press.

Smetana, J. G. (2005). Adolescent-parent conflict: Resistance and subversion as developmental process. In L. Nucci (Ed.), Conflict, contradiction, and contrarian elements in moral development and education (pp. 69-91). Mahwah, NJ: Lawrence Erlbaum Associates.

Steinberg, L. (1989). Pubertal maturation and family relations: Evidence for the distancing hypothesis. In G. Adams, R. Monetemayor, \& T. Gullotta (Eds.), Advances in adolescent development (Vol. 1, pp. 71-92). Beverly Hills, CA: Sage. 
Steinberg, L. (1990). Interdependence in the family: Autonomy, conflict, and harmony in the parent-adolescent relationship. In S. S. Feldman \& G. L. Elliot (Eds.), At the threshold: The developing adolescent (pp. 255-276). Cambridge, MA: Harvard University Press.

Vazsonyi, A. T. (2004). Parent-adolescent relations and problem behaviors: Hungary, the Netherlands, Switzerland, and the United States. Marriage and Family Review, 35, 161187.

Yahav, R. (2006). The relationship between children's and adolescents' perceptions of parenting style and internal and external symptoms. Child: Care, Health, and Development, 33, 460-471. 